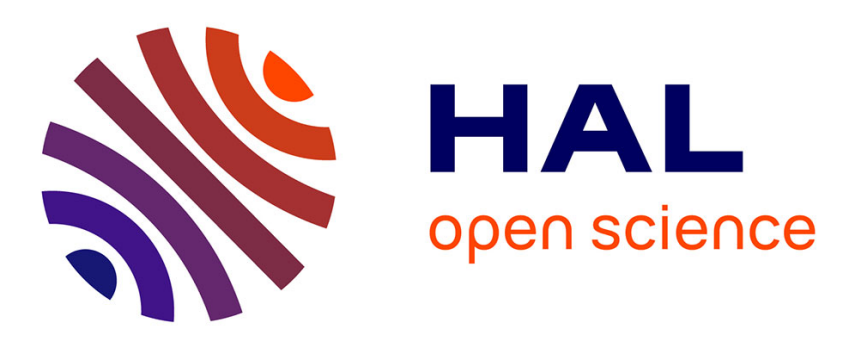

\title{
A microfluidic method generating monodispersed microparticles with controllable sizes and mechanical properties
}

\author{
Cheng Zhang, Romain A Grossier, Leda Lacaria, Felix Rico, Nadine A
}

Candoni, Stéphane A Veesler

\section{To cite this version:}

Cheng Zhang, Romain A Grossier, Leda Lacaria, Felix Rico, Nadine A Candoni, et al.. A microfluidic method generating monodispersed microparticles with controllable sizes and mechanical properties. Chemical Engineering Science, 2020, 211, pp.115322. 10.1016/j.ces.2019.115322 . hal-02179400v3

\section{HAL Id: hal-02179400 \\ https://hal.science/hal-02179400v3}

Submitted on 22 Oct 2019

HAL is a multi-disciplinary open access archive for the deposit and dissemination of scientific research documents, whether they are published or not. The documents may come from teaching and research institutions in France or abroad, or from public or private research centers.
L'archive ouverte pluridisciplinaire HAL, est destinée au dépôt et à la diffusion de documents scientifiques de niveau recherche, publiés ou non, émanant des établissements d'enseignement et de recherche français ou étrangers, des laboratoires publics ou privés. 


\title{
A microfluidic method generating monodispersed microparticles with
}

\section{controllable sizes and mechanical properties}

\author{
Cheng Zhang ${ }^{1}$, Romain Grossier ${ }^{1}$, Leda Lacaria ${ }^{2}$, Felix Rico ${ }^{2}$, Nadine Candoni ${ }^{1}$, Stéphane Veesler ${ }^{1}$ \\ ${ }^{1}$ CNRS, Aix-Marseille Université, CINaM (Centre Interdisciplinaire de Nanosciences de Marseille), \\ Campus de Luminy, Case 913, F-13288 Marseille Cedex 09, France \\ ${ }^{2}$ Adhesion and Inflammation Lab (LAI)/INSERM U1067 CNRS UMR 7333, 163, avenue de Luminy, Case \\ 937; 13288 Marseille Cedex 09, France
}

\begin{abstract}
Seeking to produce microparticles that mimic red blood cells (RBCs), we present a microfluidic method of generating monodispersed hydrogel microparticles of $\mathrm{Na}$-/Ca-alginate with controllable sizes (micrometer range) and mechanical properties. No surfactant is used. Transformation from $\mathrm{Na}$-alginate to Ca-alginate microparticles is realized via ex situ gelation, which proves essential to obtaining desired microparticle properties, such as insolubility in water and RBC-like mechanical properties. For both $\mathrm{Na}$-alginate and $\mathrm{Ca}$-alginate microparticles, a smooth surface and a porous inner structure are observed under a scanning electron microscope. A platform of microgrippers is successfully developed to manipulate the microparticles. The Young's modulus measured using an atomic force microscope on the surface of Ca-alginate microparticles is of the same order as that of RBCs.
\end{abstract}

\section{Introduction}

Microfluidics is recognized as a powerful technique to form discrete and uniform hydrogel structures at the microscale $(<100 \mu \mathrm{m})$.(Utech et al., 2015) Its main advantage is that dropletbased microfluidic systems permit generation of discrete and uniform microdroplets which are dispersed in a continuous phase.(Zhang et al., 2015) Each microdroplet can serve as the site of a gelation reaction that yields microparticles.(Håti et al., 2016; Utech et al., 2015; Yamada et al., 2012; Zhang et al., 2007) In this paper, we explore the generation of monodispersed hydrogel microparticles for potential applications in medical and biological fields.(Lee and Mooney, 2012)

Alginate is a well-known biopolymer obtained from brown algae. It has been widely applied in drug delivery and tissue engineering due to its biocompatibility, low toxicity, nonimmunogenicity, relatively low cost, and easy gelation with divalent cations such as $\mathrm{Ca}^{2+}$ (covalent cross-linking). Alginate is a linear polysaccharide containing varying amounts of 1,4linked $\beta$-D-Mannuronic acid and $\alpha$-L-Guluronic acid residues arranged in a block-wise manner along the backbone. The composition and residue sequence vary with the source.(Lee and Yuk, 2007) Seeking to control the mechanical and/or swelling properties of alginate gels, researchers have investigated covalent cross-linking with different types of molecules and cross-linking densities.(Ouwerx et al., 1998) The purpose of our study was to produce calibrated and monodispersed microparticles whose size $(5-10 \mu \mathrm{m})$ and mechanical properties ( $E=26 \pm 7 \mathrm{kPa}$ (Dulińska et al., 2006)) are similar to those of red blood cells (RBCs). This was intended to validate a cellular ultrasonic imaging setup(Monchy et al., 2018) used to assess $\mathrm{RBC}$ aggregation under in vivo and in situ flow conditions. 
Calcium alginate (Ca-alginate) was chosen for its mechanical properties.(Ouwerx et al., 1998) Alginate forms hydrogel by simple gelation with divalent cations, such as calcium cation $\left(\mathrm{Ca}^{2+}\right)$. However, direct mixing of a calcium solution with an alginate solution in a microfluidic chip gives rise to instant gelation, likely resulting in clogging and non-uniform microdroplet formation(Utech et al., 2015). To overcome this, other approaches were proposed in the literature to provide calcium (a cross-linker):

(1) dissolution of solid particles: internal gelation when solid particles of calcium carbonate are in the dispersed alginate phase, or external gelation when solid particles of calcium acetate are in the continuous phase(Zhang et al., 2007);

(2) chelation of calcium and its controlled release in the microdroplet via acidification(Utech et al., 2015) or exchange of ligands(Håti et al., 2016);

(3) injection of a buffer to delay gelation, acting as a barrier to delay calcium diffusion(Yamada et al., 2012) but requiring a complicated microfluidic chip with up to 7 inlet channels and with a risk of clogging.

Thus, in situ gelation under a microfluidic method remains an issue. Seeking to overcome this problem, we use a solvent extraction method(Freitas et al., 2005; Rondeau and Cooper-White, 2008; Sugaya et al., 2013). We develop a simple 3-step alginate microparticle synthesis. First, sodium alginate ( $\mathrm{Na}$-alginate) microdroplets of the desired size and concentration are produced without using surfactant, since surfactant has been shown to affect particle morphology(Pittermannová et al., 2016). Second, Na-alginate microparticles are obtained by microdroplet shrinkage via water extraction by dimethyl carbonate (DMC). Third, ex situ crosslinking is performed with a calcium chloride $\left(\mathrm{CaCl}_{2}\right)$ solution, which yields Ca-alginate microparticles. Here, unlike most approaches where particle size is controlled exclusively by channel size(Utech et al., 2015), the final size is controlled by channel diameter, chemical composition of the continuous phase, initial Na-alginate concentration $\left(\mathbf{C}_{\mathbf{i}}\right)$, ratio $(\mathbf{k})$ of flow rates between the continuous phase and the dispersed phase and total flow rate (фтот) of the two phases.

\section{Materials and methods}

\subsection{Chemical materials}

Sodium alginate (I3G80), dimethyl carbonate (ReagentPlus 99\%, CAS number 613-38-6,) and calcium chloride (22 317.297) were obtained from Alliance Gums and Industries, SIGMAALDRICH and PROLABO, respectively and used without further purification.

\subsection{Principle of droplet-based microfluidic system with DMC}

A droplet-based microfluidic system is constructed (Fig.1) using commercially available polyether ether ketone (PEEK) junctions and Teflon-like tubing (IDEX Health and Science) with inner diameter (ID) $150 \mu \mathrm{m}$ unless specified, initially designed for high-performance liquid chromatography (HPLC) systems. These two materials were previously tested in our group and proved to be compatible with almost all solvents, showing excellent resistance and no solvent evaporation.(Ildefonso et al., 2012)

This droplet-based microfluidic system is used to generate hydrogel microparticles dispersed in a flow of continuous phase. An aqueous $\mathrm{Na}$-alginate solution (concentration varying over 3 orders of magnitude from 0.006 to $1 \mathrm{wt} \%$ ) is used as the dispersed phase and dimethyl carbonate (DMC) as the continuous phase. Although these two phases are immiscible at room temperature, water's low solubility (3wt\%) in DMC(Stephenson and Stuart, 1986) ensures slow exchange between DMC and water. 


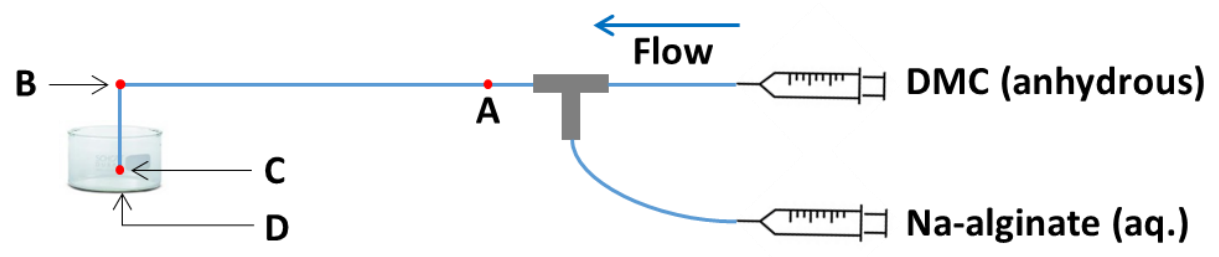

Figure 1: Diagram of the microfluidic setup where A, B, C and D are observation points after microdroplet generation, at the end of the channel, at the outlet of the channel and at the bottom of the collecting vial respectively.

\subsection{Principle of shrinkage during generation and collection of microdroplets}

Our approach is inspired by Rondeau and Cooper-White(Rondeau and Cooper-White, 2008) who studied the formation of biopolymer microparticles using DMC as continuous phase. Along the microfluidic channel, water contained in $\mathrm{Na}$-alginate microdroplets diffuses slowly into carrier fluid DMC (Fig.2). Consequently, the concentration of alginate in the microdroplets increases, assuming negligible diffusion of alginate in DMC.(Rondeau and Cooper-White, 2008) Furthermore, this mechanism allows the desired microparticle size and concentration to be obtained without using low ID channels or injecting a highly concentrated and viscous alginate solution, both of which would complicate the procedure and risk blocking microdroplets. Finally, shrunk microdroplets are collected in a DMC-containing vial, where water extraction continues. Because of the water extraction by DMC, Na-alginate microdroplets generated in the microfluidic channel shrink, becoming $\mathrm{Na}$-alginate microparticles. After gentle drying at room temperature, alginate cross-linking is realized simply by adding an aqueous $\mathrm{CaCl}_{2}$ solution, forming Ca-alginate microparticles. Figure 3 shows optical micrographs of microdroplets/particles at different observation points during the experiment. Note that separating $\mathrm{Na}$-alginate and $\mathrm{Ca}$-alginate microparticles from solution is a crucial step for potential applications(Pittermannová et al., 2016).

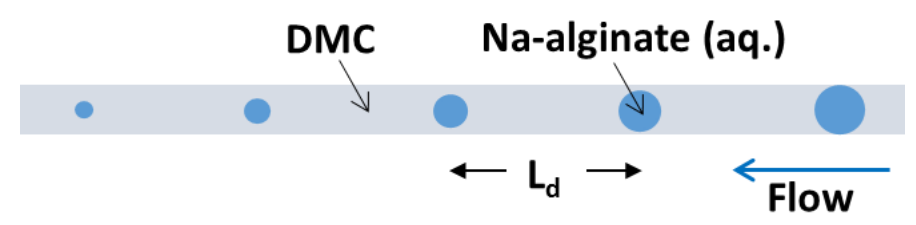

Figure 2: Schematic illustration of the shrinkage of microdroplets in DMC along the microfluidic channel where $L_{d}$ is the distance between 2 successive microdroplets.

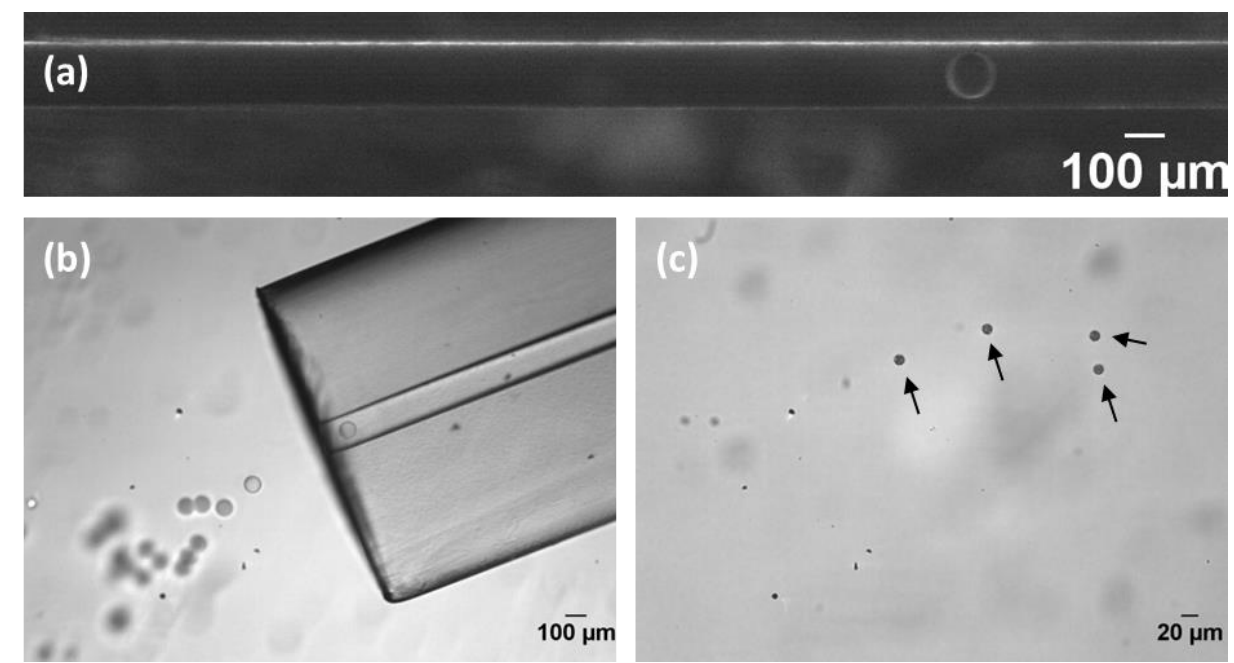


Figure 3: Optical micrographs of $\mathrm{Na}$-alginate microdroplets $\left(\mathbf{C}_{\mathrm{i}}=0.06 \mathrm{wt} \%\right)$ in $\mathrm{DMC}$ in a channel (ID $150 \mu \mathrm{m})(\mathrm{a})$ after generation (point $\mathbf{A}$ in Fig.1) and (b) at the outlet of the channel (point $\mathbf{C}$ in Fig.1) during collection in DMC. (c) Na-alginate microparticles (d=11.7 $\mu \mathrm{m} \pm 1.9 \%)$ in DMC, after complete shrinkage, at the bottom of the collecting vial (point $\mathbf{D}$ in Fig.1).

\subsection{Characterization of microparticles}

\subsubsection{Scanning electron microscope}

The topology and inner structure of microparticles are observed by scanning electron microscope (SEM, JEOL 6340F), with a low acceleration voltage of $1 \mathrm{kV}$ and without coating. After drying at room temperature in air, microparticles are fixed to the bottom of a recipient. They are then transferred to a copper sample plot with carbon tape. This step may break some microparticles, revealing the inner structure. A razor blade is also used to cut microparticles to observe the inner structure.

\subsubsection{Microgrippers}

The mechanical properties of microparticles are first evaluated using microgrippers (FT-G 102 Force Sensing Microgrippers from FemtoTools). Alginate microparticles, placed in a glass petri dish filled with aqueous solution, are observed under a transmission optical microscope.

\subsubsection{Atomic force microscope}

The mechanical properties of microparticles are also characterized by measuring the Young's modulus using a NanoWizard atomic force microscope (JPK, Bruker, Santa Barbara, CA, USA). The experiment involves the use of a V-shaped cantilever, an MLCT-Bio-DC(C) (Bruker, Santa Barbara, CA, USA) with a pyramidal probe and a spring constant of $0.01 \mathrm{~N} / \mathrm{m}$. Microparticles are deposited on a surface and observed via an inverted optical microscope coupled with AFM.

\section{Results and discussion}

\subsection{In-channel microdroplet shrinkage}

We discuss here in detail the shrinkage of spherical microdroplets in the microfluidic channel. For each microdroplet, water diffuses both left and right in the channel (Fig.4 (a)). To facilitate the calculation, we consider that water diffuses exclusively in one direction, either left or right (Fig.4 (b)), until DMC is saturated.

\section{(a)}

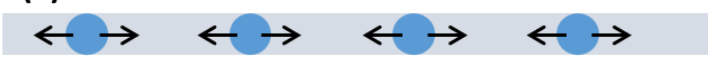

(b)

Figure 4: Illustration of water diffusion (a) in reality and (b) for simplified calculation during extraction by $\mathrm{DMC}$ in the channel.

Thus, the quantity of DMC in the volume between two microdroplets $\left(\mathbf{V}_{\mathbf{d}}\right)$, related to the distance between two microdroplets $\left(\mathbf{L}_{d}\right)$, determines the maximum quantity of water that can be extracted from one microdroplet. For a microfluidic channel of inner diameter $\mathbf{d}, \mathbf{V}_{\mathbf{d}}$ is calculated with the equation (1).

$V_{d}=L_{d} \times \pi(d / 2)^{2}$

Obviously, given the limited solubility ( $3 w t \%)$ of water in DMC, a certain $\mathbf{L}_{d}\left(\right.$ or $\left.\mathbf{V}_{d}\right)$ is required to achieve the desired decrease in diameter (or volume) of microdroplets. 
We demonstrate here a method of estimating the required $\mathbf{L}_{d}$ to obtain a given reduction in diameter after shrinkage of microdroplets of initial diameter $\mathbf{d}_{\mathbf{i}}$. Because diffusion of $\mathrm{Na}$ alginate in DMC is negligible(Rondeau and Cooper-White, 2008), the decrease in microdroplet diameter (or volume) is only due to water extraction by DMC. The desired diameter is attained when DMC is saturated by water. This equilibrium state is described by equation (2), which indicates that the volume of water diffused to DMC determines the reduction in microdroplet volume $\mathbf{R}_{\mathbf{v}}(\%)$ :

$\mathbf{V}_{\mathbf{d}} \times 3 \%=(4 / 3) \pi\left(\mathbf{d}_{\mathrm{i}} / 2\right)^{3} \times \mathbf{R}_{\mathbf{v}}(\%) \quad(2)$

As a first approximation, we assume that the initial diameter $\mathbf{d}_{\mathbf{i}}$ of the microdroplets generated is close to the channel ID $\left(\mathbf{d}_{\mathbf{i}} \approx \mathbf{d}\right)$. Then, by combining equation (1) and (2), we get equation (3) showing the ratio between required microdroplet distance $L_{d}$ and initial microdroplet diameter $\mathbf{d}_{\mathbf{i}}$.

$\mathbf{L}_{\mathrm{d}} / \mathbf{d}_{\mathbf{i}} \approx \frac{2}{9} \mathbf{R}_{\mathbf{v}}$

As an example, there is a $90 \%$ decrease in diameter, from microdroplets with a diameter of $150 \mu \mathrm{m}$ to microparticles with the same diameter range as RBCs (e.g. $15 \mu \mathrm{m})$. This corresponds to a $99.97 \%$ decrease in volume $\mathbf{R}_{\mathbf{v}}$. Therefore, according to the theoretical calculation (3), the $\mathrm{L}_{\mathrm{d}} / \mathrm{d}_{\mathrm{i}}$ ratio required is:

$\mathrm{L}_{\mathrm{d}} / \mathrm{d}_{\mathrm{i}} \approx 22.2$

\subsection{Operating parameters required to obtain desired microdroplet diameter}

The channel containing microdroplets and DMC is observed at points $\mathbf{A}$ and $\mathbf{B}$, situated $5 \mathrm{~cm}$ and $63 \mathrm{~cm}$ respectively from the outlet of T-junction (Fig.1).

\subsubsection{Controlling the distance between microdroplets $L_{d}$}

Experiments are conducted to study the generation of microdroplets at point $\mathbf{A}$, by varying the flow rates of dispersed phase $\phi_{D}$ and continuous phase $\phi_{c}$ (Fig.S1 in the supplementary material). $\phi_{D}$ is varied from 0.001 to $0.3 \mu \mathrm{L} / \mathrm{s}$ and $\phi_{c}$ from 0.01 to $0.6 \mu \mathrm{L} / \mathrm{s}$. For each pair ( $\phi_{D}$ and the corresponding $\left.\phi_{c}\right), L_{d}$ is measured at point $\mathbf{A}$. Each pair corresponds to a given ratio $\mathbf{k}$ $\left(\phi_{\mathrm{C}} / \phi_{\mathrm{D}}\right)$. Regarding the total flow rate $\phi_{\text {Tот }}\left(\phi_{\mathrm{D}}+\phi_{\mathrm{C}}\right)$, our pairs are divided into two groups with low and high values of $\phi_{\text {тот. }}$ Plotting $L_{d} / d_{i}$ versus $\mathbf{k}$ for each range of $\phi_{\text {тот }}$ (Fig.S2 in the supplementary material) shows an increase in $\mathbf{L}_{\mathbf{d}} / \mathbf{d}_{\mathbf{i}}$ with $\mathbf{k}$, with a linear relationship and slope depending on $\phi_{\text {тот. }}$. This result is consistent with our previous findings on the influence of $\phi_{D} / \phi_{C}$ (i.e. $\mathbf{1 / k}$ ) and $\phi_{\text {тот }}$ on microdroplet diameter $\mathbf{d}_{\mathbf{i}}$.(Zhang et al., 2015)

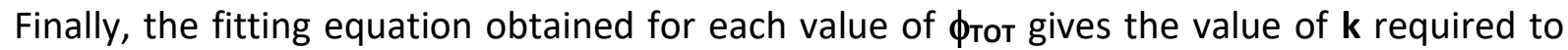
reach $L_{d} / d_{i}=22.2$ (Eq. (4)), corresponding to a volume reduction of $99.97 \%$ (crosses in Fig.S2 in the supplementary material). This means that with a low and a high total flow rate, a value of 21 and 38 for $k$ respectively ensures a volume reduction of $99.97 \%$. Moreover, assuming a maximum reduction of volume $\mathbf{R}_{\mathbf{v}}<100 \%$ for the final microparticle, equation (3) demonstrates that this $\mathbf{R}_{\mathbf{v}}$ is attainable with $\mathbf{L}_{d} / \mathbf{d}_{i}<22.3$. This is why the fitting curves are stopped at $\mathbf{L}_{d} / \mathbf{d}_{i}<22.3$. However, loss of water takes time, and meanwhile the microdroplet is moving forward in the channel. Therefore, the length of channel required to reach the final diameter depends on flow rates, as discussed below.

\subsubsection{Influence of residence time on shrinkage rate}

For a given $\mathbf{k}$, microdroplets are observed at points $\mathbf{A}$ and $\mathbf{B}$. Figure 5 shows optical

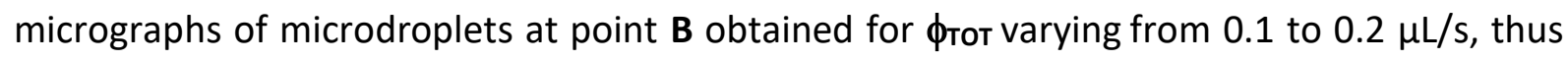
between the two $\phi_{\text {тот }}$ ranges described above (see fitting curves). Because of $\mathbf{k}$ values $(20,30$ 
and 40$), L_{d}$ is too large to be photographed for measurement. Nevertheless, microdroplet shrinkage is observed for all three values of $\mathbf{k}$. According to optical micrographs taken at points A and B, microdroplet volume reduces $17 \%, 71 \%$ and $99 \%$ respectively for $\mathbf{k}$ of 20,30 and 40 . Thus, microdroplet shrinkage or water loss increases with k. Moreover, the significant shrinkage for $\mathbf{k}=40$ is confirmed by observation of microdroplets at different points along the channel (between A and B), as shown in Figure S3 of the supplementary material. The final microparticle diameter is about $10 \mu \mathrm{m}$, which is in the same range as RBCs.

However, assuming $L_{d} / d_{i}=22.2$ (eq. (4)) for $\mathbf{R}_{\mathbf{v}}$ of $99.97 \%$, i.e. a diameter reduction of $90 \%$ (crosses in Fig. 5), experiments should lead to a diameter reduction of around $50 \%, 80 \%$ and almost $100 \%$ for $\mathbf{k}$ of 20,30 and 40 , respectively. Obviously, the real shrinkage rate at point $\mathbf{B}$ is lower than that calculated. This is probably due to the insufficient residence time $\tau$ of microdroplets in the channel between points $\mathbf{A}$ and $\mathbf{B}$, which limits the loss of water. Moreover, $\tau$ decreases with $\phi_{\text {тот }}$ since the distance between $\mathbf{A}$ and $\mathbf{B}$ is fixed. Therefore, we can either increase the channel length or continue the shrinkage by collecting microdroplets in DMC.

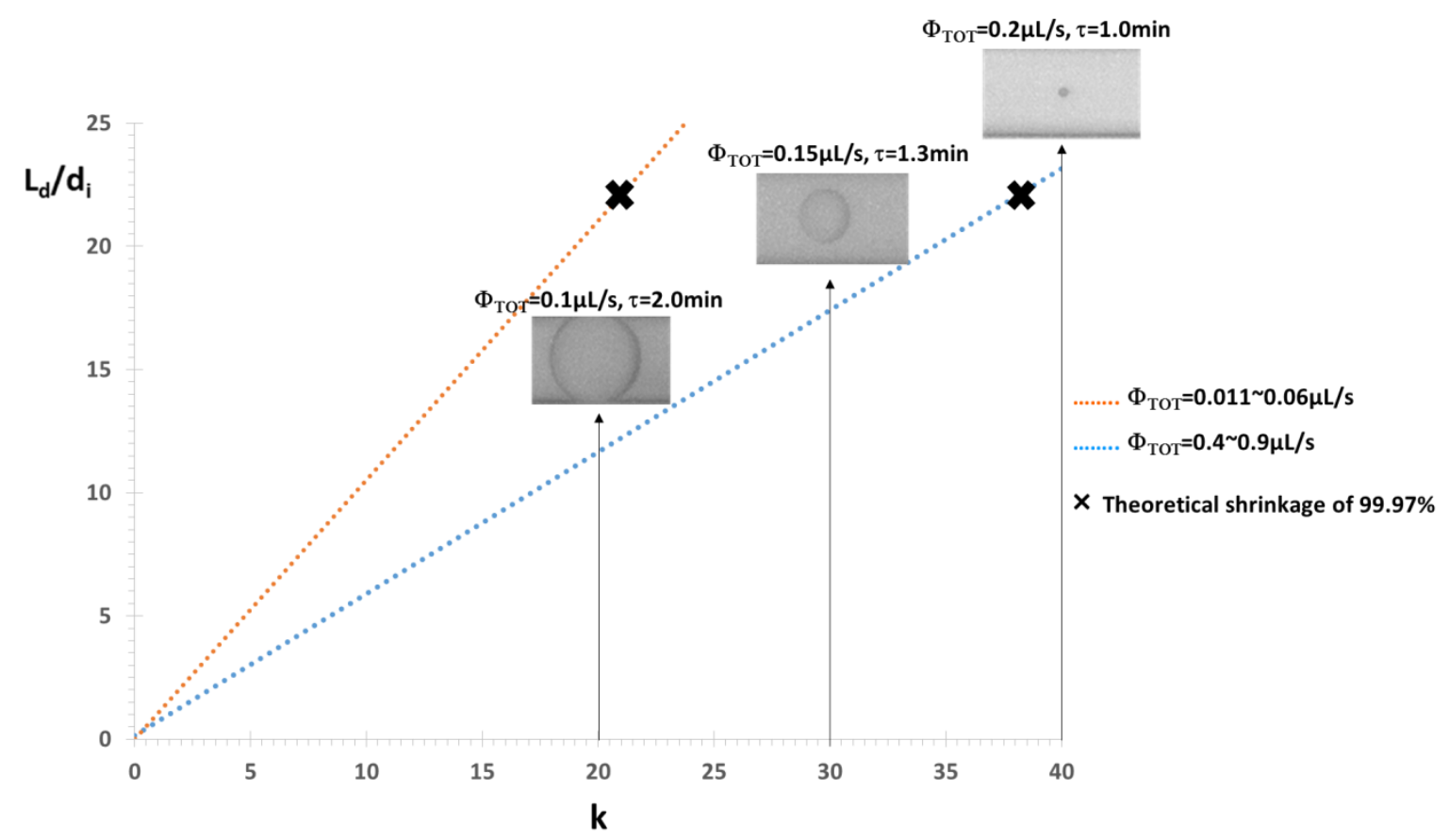

Figure 5: Fitting of $L_{d} / d_{i}$ versus $\mathbf{k}$ for two range values of $\phi_{\text {TOт }}$ from figure S2 with observations of microdroplets at point B $\left(63 \mathrm{~cm}\right.$ from T-junction outlet, Fig.1) for $\phi_{\text {TOT }}$ from 0.1 to $0.2 \mu \mathrm{L} / \mathrm{s}$. Markers $(x)$ correspond to theoretical shrinkage of $99.97 \%$ in microdroplet volume, i.e. $90 \%$ diameter reduction $\left(L_{d} / d_{i}=22.2\right) . \tau$ : Residence time of microdroplets in the channel. (Initial Na-alginate concentration $\mathrm{C}_{\mathrm{i}}=0.02 \mathrm{wt} \%$, channel length $\mathrm{L}=70 \mathrm{~cm}$.)

However, a long channel causes fluid instability, probably because of the pressure drop. For instance, microdroplets at the end of the channel for $\mathbf{k}=40$ and $\phi_{\mathrm{TOT}}=0.205 \mu \mathrm{L} / \mathrm{s}$ are observed to approach each other, forming aggregations because no surfactant is used (Fig S4 in the supplementary material). They flow together towards the outlet, despite the fact that they start out relatively far from each other due to the high value of $L_{d}$. Actually, because of shrinkage, when microdroplet diameter becomes too small compared to channel ID, microdroplets can move towards the inner wall of the channel and may be affected by 
contamination there. Our experience indicates that a clean channel is key to avoiding the aggregation of microdroplets. Thus, careful cleaning of the channel with ethanol before experiments is highly recommended, especially when a high $\mathbf{k}$ is required. Contrastingly, for low values of $\mathbf{k}$, the main risk is coalescence of microdroplets when leaving the channel. This can be prevented by gentle hydrodynamic agitation. Thus, in addition to the careful choice of $\mathbf{k}$, certain operating techniques also play a role in achieving desired microparticle size.

\subsection{Shrinkage during collection: from microdroplets to microparticles of $\mathrm{Na}$-alginate}

When collected in DMC, Na-alginate microdroplets continue to shrink and eventually form spherical $\mathrm{Na}$-alginate microparticles. For the experimental condition of $\mathrm{C}_{\mathrm{i}}=0.25 \mathrm{wt} \%$, DMC flow rate $=0.15 \mu \mathrm{L} / \mathrm{s}, \mathbf{k}=30$ and $\mathrm{L}=20 \mathrm{~cm}, \mathbf{d}_{\mathrm{f}}$ is measured on a sampling of about 2386 microparticles and monodisperse size distribution is revealed (Figure 6).

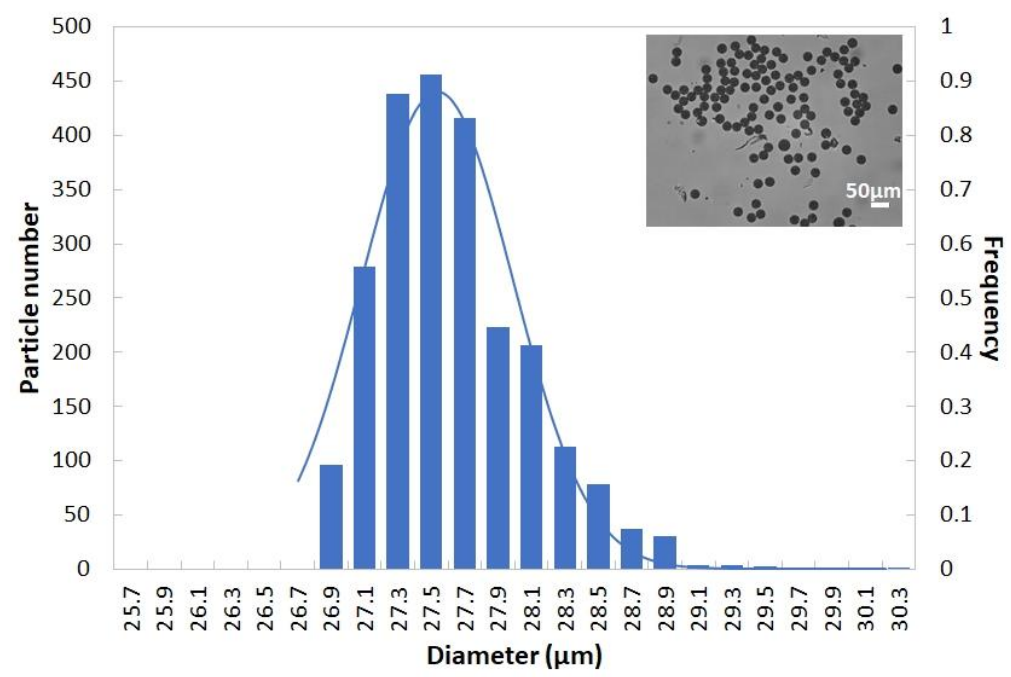

Figure 6: Size distribution of Na-alginate microparticles. The microparticles are illustrated in the inset. $d_{f}=27.5 \mu \mathrm{m} \pm 0.5 \mu \mathrm{m}$. The curve shows the Gaussian fitting. Experimental conditions: $\mathbf{C}_{\mathbf{i}}=0.25 \mathrm{wt} \%, \mathrm{DMC}$ flow rate $=0.15 \mu \mathrm{L} / \mathrm{s}, \mathbf{k}=30$ and $\mathrm{L}=20 \mathrm{~cm}$. Result based on 2386 microparticles produced at a frequency of 2 microparticles/s without using surfactant.

Initial values of microdroplet diameter $\left(\mathbf{d}_{i}\right)$ and Na-alginate concentration $\left(\mathbf{C}_{\mathbf{i}}\right)$ are varied to study their effect on final microparticle diameter $\left(\mathbf{d}_{\boldsymbol{f}}\right)$ and concentration $\left(\mathbf{C}_{\boldsymbol{f}}\right)$ after collection. For the experiments in Figure 7 , microdroplets of $d_{i}$ from 110 to $220 \mu m$ are generated with $\mathbf{C}_{i}$ of $\mathrm{Na}$-alginate solutions varying from 0.006 to $1 \mathrm{wt} \%$. For each experiment, $\mathbf{d}_{\mathbf{f}}$ is measured on a sampling of about 50 microparticles. It is noteworthy that spherical microparticles with a post-collection diameter $\mathbf{d}_{\mathbf{f}}$ of $7.7 \mu \mathrm{m} \pm 0.3 \mu \mathrm{m}$ are obtained with $\mathbf{C}_{\mathbf{i}}=0.006 \mathrm{wt} \%$ (Fig. 10a and $10 \mathrm{~b})$, indicating that RBC size can be reached using this process. Moreover, Figure 7a shows that $\mathbf{d}_{\mathbf{f}}$ increases with both $\mathbf{C}_{\mathbf{i}}$ and $\mathbf{d}_{\mathbf{i}}$. Similar results were previously found for porous microparticles of Na-poly(styrenesulfonate) formed by inkjet injection(Yang et al., 2015). In our study, for each $\mathbf{C}_{\mathbf{i}}, \mathbf{d}_{\mathbf{f}}$ versus $\mathbf{d}_{\mathbf{i}}$ is fitted by a power law. According to the fitting equations, the exponent is about 0.3-0.4 for all $\mathbf{C}_{\mathbf{i}}$, whereas the constant factor increases with $\mathbf{C}_{\mathbf{i}}$ (Fig.7a). Since $\mathbf{d}_{\boldsymbol{f}}$ does not greatly vary with $\mathbf{d}_{\boldsymbol{i}}$ when $\boldsymbol{C}_{\boldsymbol{i}}$ is fixed, a mean value of $\mathbf{d}_{\boldsymbol{f}}$ is calculated for each $\mathbf{C}_{\mathbf{i}}$ and plotted versus $\mathbf{C}_{\mathbf{i}}$ (Fig.7b). This leads to another power law dependence. This curve 
enables the initial concentration of $\mathrm{Na}$-alginate to be defined so as to obtain a given final microparticle size.
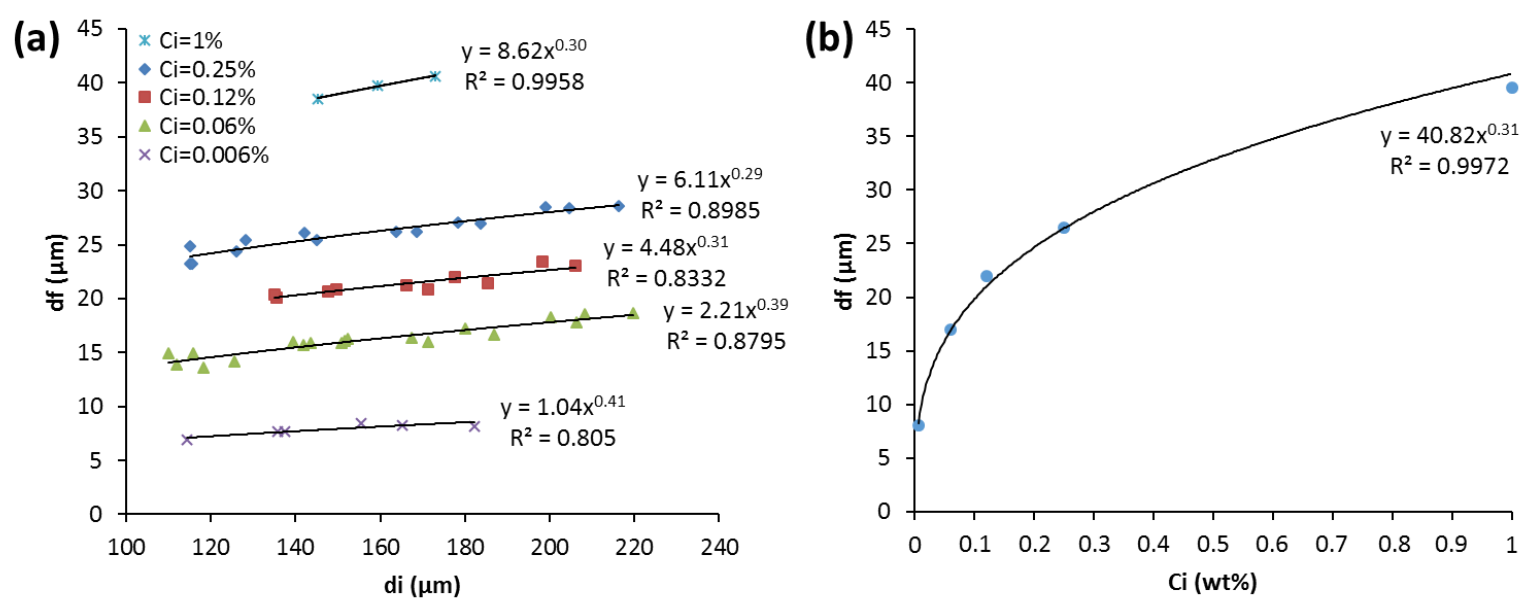

Figure 7: (a) Final microparticle size $\mathbf{d}_{\mathrm{f}}$ as a function of initial microdroplet size $\mathbf{d}_{\mathbf{i}}$ for different $\mathrm{Na}$ alginate concentrations $\mathbf{C}_{\mathbf{i}}\left(0.006\right.$ to $1 \mathrm{wt} \%$ ); (b) Plot of final microparticle mean diameter $\mathbf{d}_{\mathbf{f}}$ after collection versus initial $\mathrm{Na}$-alginate concentration $\mathbf{C}_{\mathbf{i}}$.

In addition, the final concentration of $\mathrm{Na}$-alginate $\left(\mathbf{C}_{\mathrm{f}}\right)$ in the microparticle after collection is estimated from initial and final volumes of the microdroplet $\left(\mathbf{V}_{\mathbf{i}}\right.$ and $\left.\mathbf{V}_{\mathbf{f}}\right)$, considering that the quantity of $\mathrm{Na}$-alginate in the microdroplet remains constant. Therefore, we assume as above that water diffusion from microdroplets to $D M C$ is the only mass transfer. Then $\mathbf{C}_{\boldsymbol{f}}$ is given by equation (5).

\section{$\mathrm{C}_{\mathrm{f}}=\mathrm{C}_{\mathrm{i}} \times\left(\mathbf{d}_{\mathrm{i}} / \mathbf{d}_{\mathrm{f}}\right)^{3} \quad(5)$}

From data in Figure 7a and equation (5), $\mathbf{C}_{\mathbf{f}}$ is calculated for different $\mathbf{d}_{\mathbf{i}}$ and $\mathbf{C}_{\mathbf{i}}$ (Figure 8). It is obvious that $\mathbf{C}_{\mathbf{f}}$ depends drastically on $\mathbf{d}_{\mathbf{i}}$, whatever the value of $\mathbf{C}_{\mathbf{i}}$. Thus, a power law fits all the points without distinction between $\mathbf{C}_{\mathbf{i}}$ values. Note that the fitting equation can be derived from those in Fig.7a (mathematical derivation in the supplementary material). This curve enables the initial size of droplets to be defined so as to obtain a given final concentration of $\mathrm{Na}$-alginate in microparticles. This final concentration is important, as it can affect the mechanical properties of the microparticles. Thus, the initial size of droplets determines the final concentration of $\mathrm{Na}$-alginate in microparticles, which in turn may control microparticle mechanical properties. 


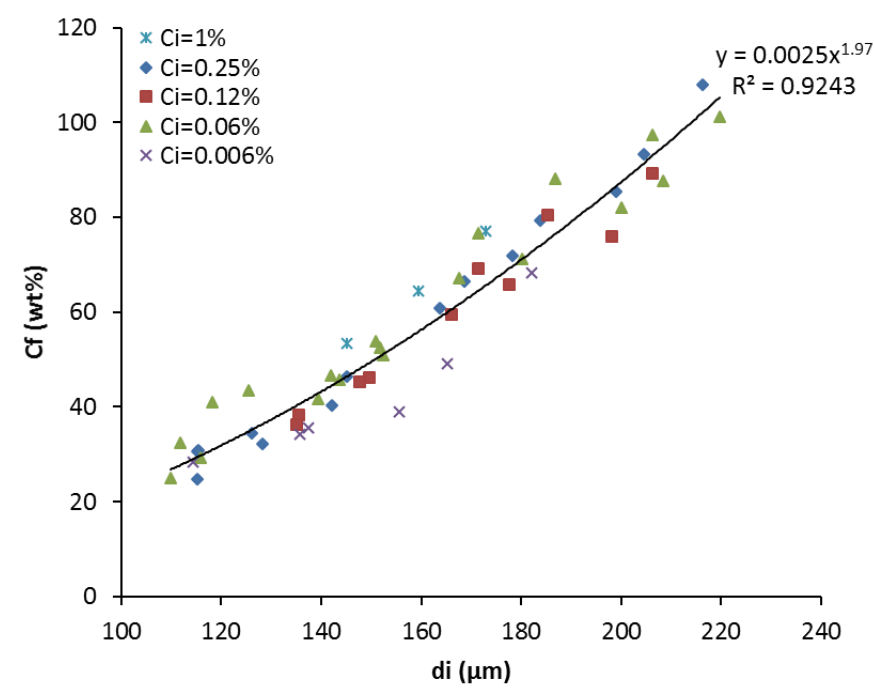

Figure 8: Relationship between the calculated final Na-alginate concentration $\mathbf{C}_{\mathbf{f}}$ in the microparticle and the initial diameter $\mathbf{d}_{i}$ of droplets with different initial concentrations $\mathbf{C}_{i}$, with the fitting curve of all data.

\subsection{From Na-alginate microparticles to Ca-alginate microparticles}

All the Na-alginate microparticles are observed to be soluble in water, which limits the chemical composition of the media used in further research or applications. To optimize, we therefore use a divalent cation, $\mathrm{Ca}^{2+}$ here, for alginate gelation.

\subsubsection{Formation of $\mathrm{Ca}$-alginate microparticles by cross-linking with a $\mathrm{CaCl}_{2}$ solution}

After total evaporation of DMC, an aqueous $\mathrm{CaCl}_{2}$ solution is added to the collecting vial containing dried $\mathrm{Na}$-alginate microparticles. The cation of calcium $\left(\mathrm{Ca}^{2+}\right)$ induces cross-linking (Yang et al., 2015), thus transforming $\mathrm{Na}$-alginate microparticles into Ca-alginate microparticles. Immediate swelling is observed when $\mathrm{CaCl}_{2}(0.5 \%, 1 \%$ or $10 \mathrm{wt} \%)$ is added. The diameter of microparticles increases from $28.7 \mu \mathrm{m} \pm 0.3 \mu \mathrm{m}$ (measured on 51 microparticles) before cross-linking (dried microparticles obtained with $\mathbf{C}_{\mathbf{i}}=0.25 \mathrm{wt} \%, \mathbf{k}=5$ and $\phi_{\text {тот }}=0.06 \mu \mathrm{L} / \mathrm{s}$ ) $33.4 \mu \mathrm{m} \pm 0.4 \mu \mathrm{m}$ (measured on 51 microparticles) after immersion and cross-linking (Fig.9 for $0.5 \mathrm{wt} \%$ of $\mathrm{CaCl}_{2}$ ). The results are identical whatever the $\mathrm{CaCl}_{2}$ concentration: it has no obvious effect on either the shape or the size of final Ca-alginate microparticles. Unlike Na-alginate microparticles, all the Ca-alginate microparticles are observed to be insoluble in water. This holds promise for future applications in water.
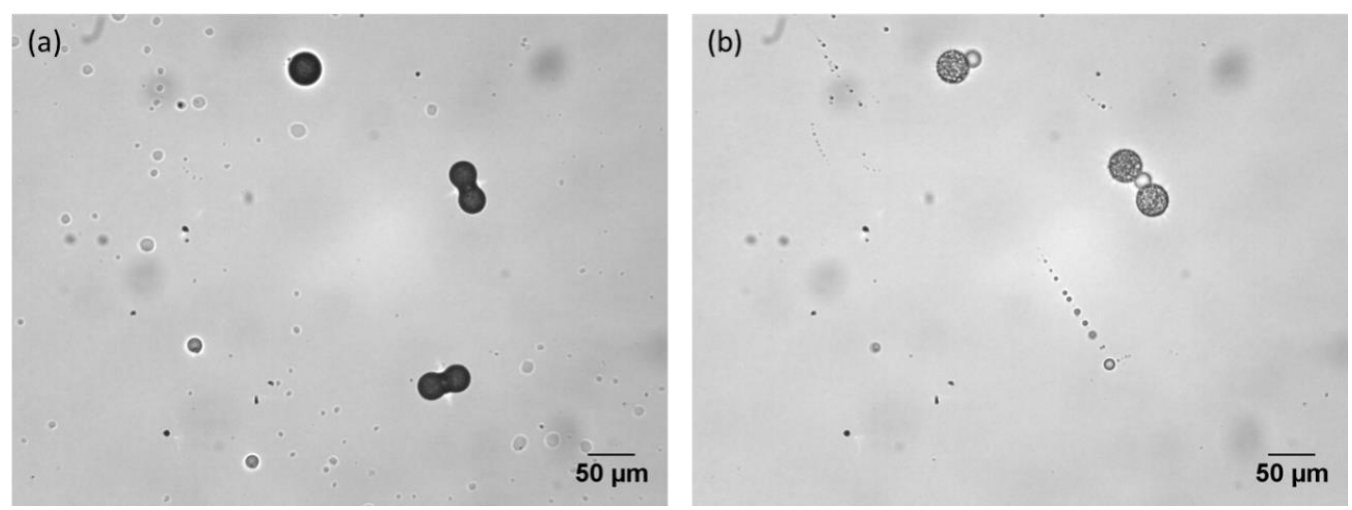


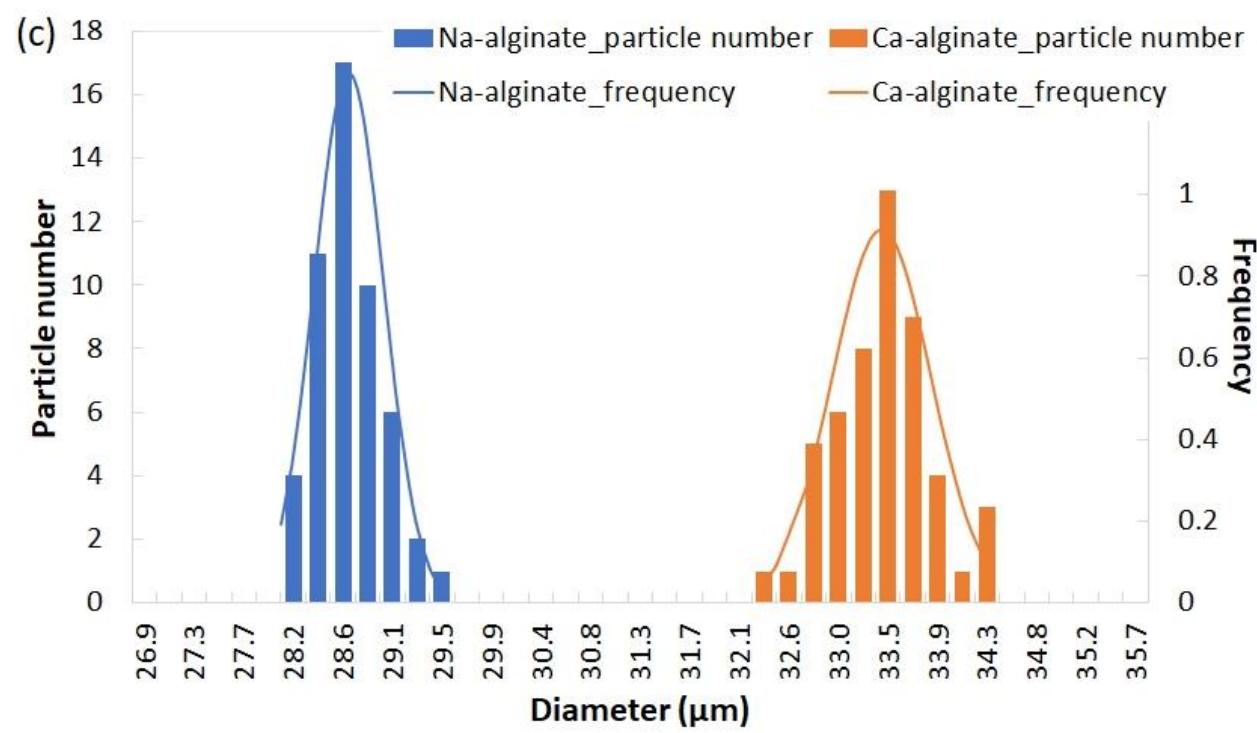

Figure 9: Images of (a) dried Na-alginate microparticles and (b) Ca-alginate microparticles after immersion in $\mathrm{CaCl}_{2}$ solution (0.5wt\%). (c) Size distribution of $\mathrm{Na}$-alginate and $\mathrm{Ca}$-alginate microparticles (measured on 51 microparticles). The curves show the Gaussian fitting. Experimental conditions: $\mathbf{C}_{\mathbf{i}}$ $=0.25 \mathrm{wt} \%$, DMC flowrate $=0.05 \mu \mathrm{L} / \mathrm{s}$ and $\mathbf{k}=5$.

It is noteworthy that gelation was also achieved for small $\mathrm{Na}$-alginate microparticles $(7.7 \mu \mathrm{m} \pm 0.3 \mu \mathrm{m})$ whose diameter is close to that of RBCs (Fig.7, 10a and 10b). Observations lead to the same conclusion: immediate swelling after immersion in $\mathrm{CaCl}_{2}$ (Fig.10c). However, due to the difficulty of observation and measurement of the Ca-alginate microparticles produced in this experimental condition, we cannot provide quantitative data regarding size and mechanical properties on these microparticles.
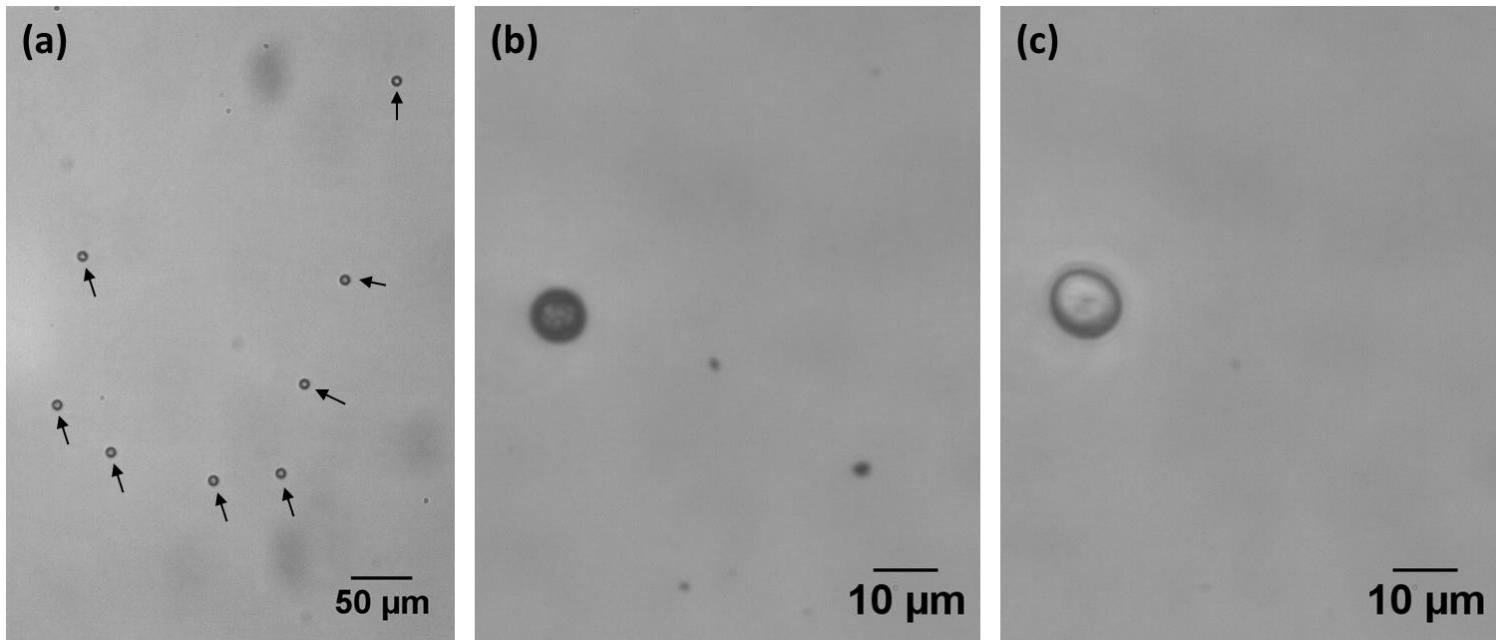

Figure 10: (a) Alginate microparticles in DMC; (b) a dried alginate microparticle; (c) the same microparticle as in (b) immersed in $\mathrm{CaCl}_{2}(1.35 \mathrm{wt} \%)$. Experimental conditions: $\mathrm{C}_{\mathrm{i}}=0.006 \mathrm{wt} \%$, DMC flow rate $=0.15 \mu \mathrm{L} / \mathrm{s}, \mathrm{k}=30, \mathrm{~L}=30 \mathrm{~cm}$.

\subsubsection{Characterization of $\mathrm{Na}$-alginate and $\mathrm{Ca}$-alginate microparticles}

In addition to the optical microscope, the scanning electron microscope (SEM) is also used to observe the topology and the inner structure of microparticles. Furthermore, preliminary 
attempts to characterize microparticle mechanical properties are carried out using microgrippers.

\subsubsection{Topology of $\mathrm{Na}$-alginate and $\mathrm{Ca}$-alginate microparticles}

SEM images (Fig.11) show that both $\mathrm{Na}$-alginate and $\mathrm{Ca}$-alginate microparticles are spherical with a smooth surface. Ca-alginate microparticles are slightly smaller than $\mathrm{Na}$-alginate microparticles, which seems inconsistent with the swelling previously observed (Fig.9). This can be explained by the manipulating conditions under vacuum in SEM. Because water remaining in the microparticle is extracted and quickly evaporates, there is a second shrinkage after production, until a new equilibrium is reached. This second shrinkage sometimes even causes deformation in the microparticle surface (Fig.S6 in the supplementary materials), depending on microparticle properties such as diameter and concentration. This is why, for both $\mathrm{Na}$-alginate and Ca-alginate microparticles, the diameter measured by SEM is smaller than that measured by optical microscope. Moreover, SEM measurements show Na-alginate microparticles to be larger than the corresponding Ca-alginate ones, suggesting that $\mathrm{Ca}$ alginate microparticles lose more water due to the vacuum.
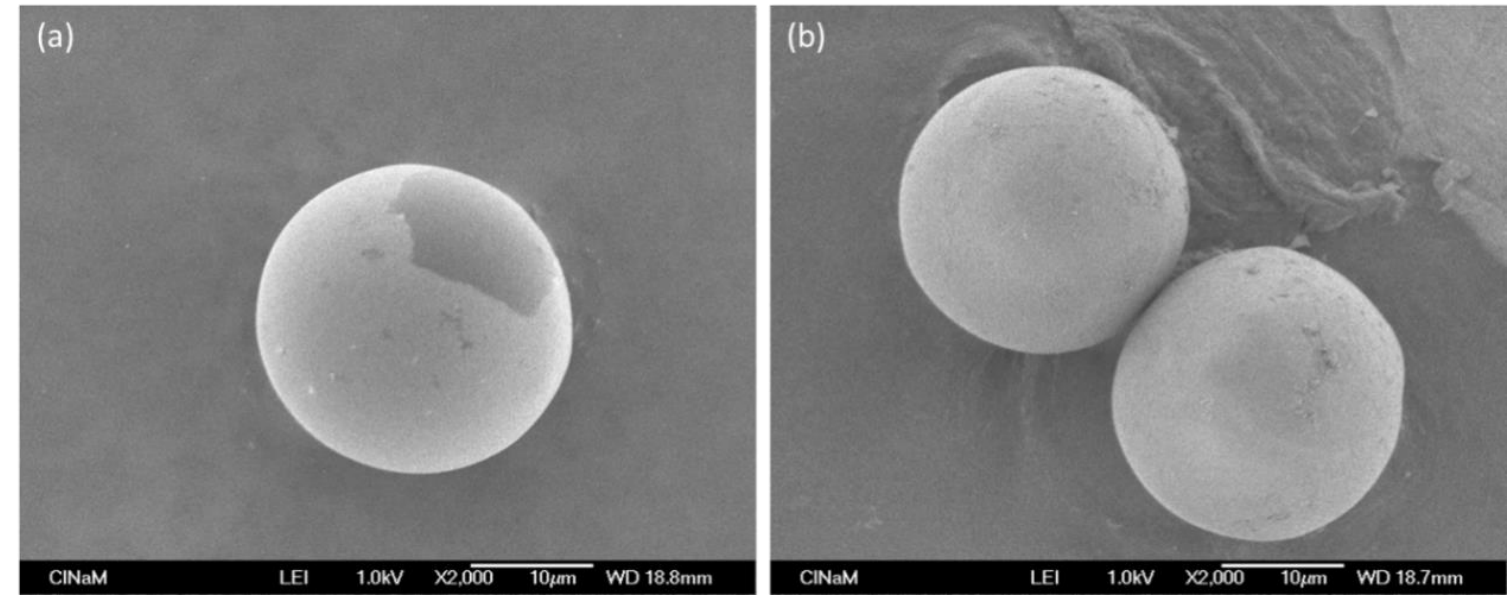

Figure 11: SEM photographs of (a) Na-alginate and (b) Ca-alginate microparticles (formed in a $0.5 \mathrm{wt} \%$ $\mathrm{CaCl}_{2}$ solution). (Same experimental conditions as for Figure 9)

\subsubsection{Inner structure of $\mathrm{Na}$-alginate and $\mathrm{Ca}$-alginate microparticles}

Observations of an Na-alginate microparticle in DMC under optical microscope (Fig.S5 in the supplementary material) and a dried one under SEM (Fig.12 (a)) reveal a porous inner structure in both cases. We therefore propose the following mechanism of microparticle formation, in accordance with Yang et al.(Yang et al., 2015) First, after Na-alginate microdroplets are generated, water moves from the microdroplets to DMC. Within the microdroplets, this water movement also induces the migration of alginate molecules towards the interface with DMC. As a result, 1) an outer shell of alginate forms gradually until it becomes so dense that water can no longer be extracted and therefore remains trapped inside; 2) several inner areas become vacant after the alginate migrates, which explains the observation of pores. The inner structure of Ca-alginate microparticles is also observed to be porous (Fig.12 (b) and Fig.S7 in the supplementary material), suggesting that cross-linking by calcium cation does not influence microparticle inner structure. 

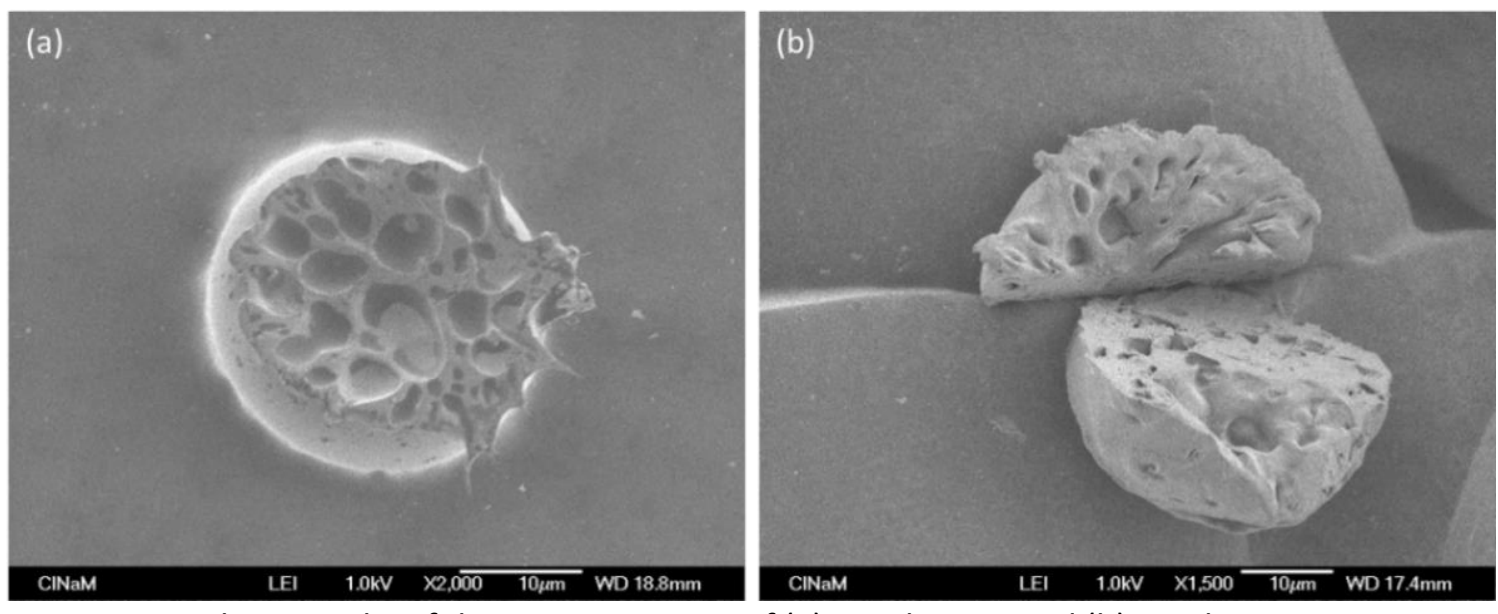

Figure 12: SEM photographs of the inner structure of (a) Na-alginate and (b) Ca-alginate microparticles (formed in a $0.5 \mathrm{wt} \% \mathrm{CaCl}_{2}$ solution). (Same experimental conditions as for Figure 9)

\subsubsection{Mechanical properties evaluated by microgrippers}

After drying, Na-alginate and Ca-alginate microparticles are grasped with force sensing microgrippers to estimate their mechanical properties (Fig.S8 in the supplementary material). Using a 6D positioning system, the microgrippers are placed around the microparticle to be tested. Depending on the voltage supplied to the microgripper left arm (0-170V), the microparticle is grasped and the force sensor of the right arm provides applied force of up to $250 \mu \mathrm{N}$. This applied force combined with the optical observation provides access to the microparticle reaction to the compression. For the Na-alginate microparticle (Fig.13), we observed (Fig.13 (c)) slipping of the left gripper arm, which indicates a strong resistance to the maximum applied force of $250 \mu \mathrm{N}$. For both $\mathrm{Na}$-alginate and $\mathrm{Ca}$-alginate microparticles manipulated by microgrippers, no overall deformation was observed.
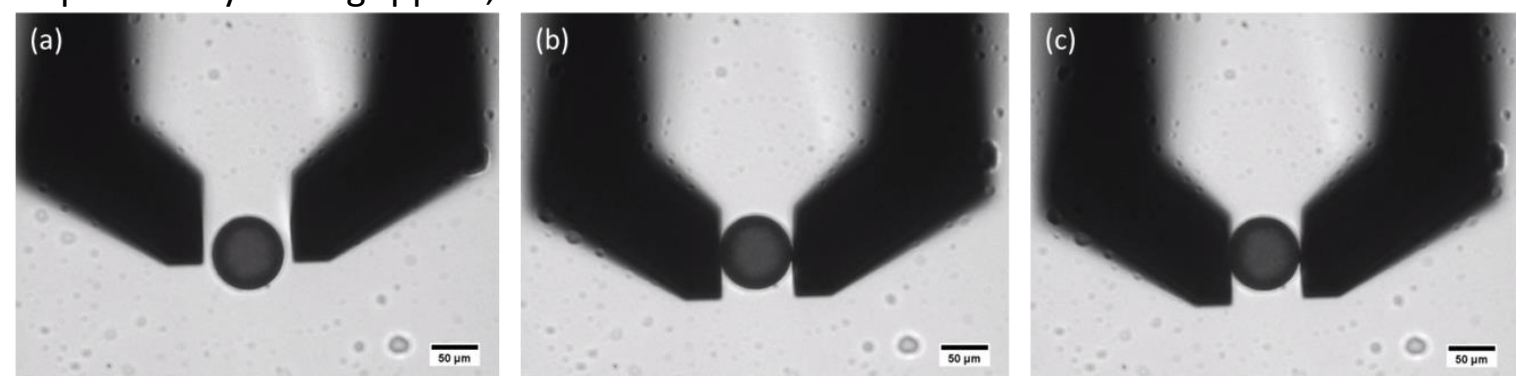

Figure 13: A dried Na-alginate microparticle $\left(d_{f}=78.7 \mu m, C_{i}=0.25 w t \%, D M C\right.$ flow rate $=1.5 \mu \mathrm{L} / \mathrm{s}, k=50$, $\mathbf{L}=30 \mathrm{~cm}$ in a capillary with inner diameter (ID) $500 \mu \mathrm{m}$ ) between microgrippers during (a) approach, (b) contact and (c) force-controlled gripping.

\subsubsection{Mechanical properties measured by AFM}

The Young's moduli of both $\mathrm{Na}$-alginate and $\mathrm{Ca}$-alginate microparticles are measured by AFM. All measurements are performed under the same force of $0.4 \mathrm{nN}$, an approach velocity of $2 \mu \mathrm{m} / \mathrm{s}$ and a $z$ length of $1 \mu \mathrm{m}$. An $8 \times 8$ force curve grid (points $2.5 \mu \mathrm{m}$ apart) is acquired in the center of the microparticle (Fig.14 (b)). Each point is measured 5 times to obtain 5 force curves/point. 

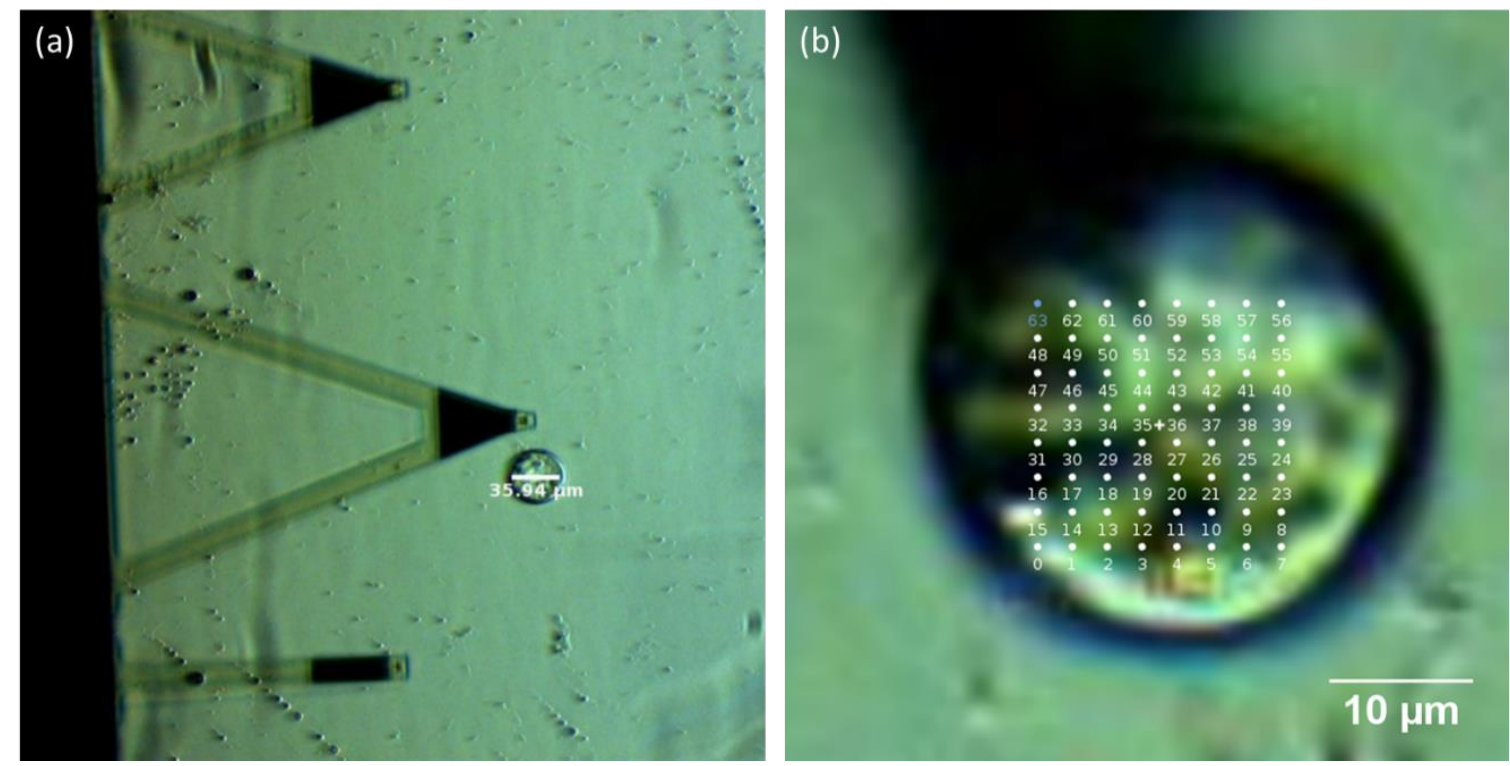

Figure 14: Image of (a) the cantilever used for the force measurement by AFM and a Ca-alginate microparticle in water $\left(\mathrm{C}_{\mathbf{i}}=0.25 \mathrm{wt} \%\right.$, DMC flow rate $=0.15 \mu \mathrm{L} / \mathrm{s}, \mathbf{k}=50, \mathrm{~L}=19 \mathrm{~cm}$ and $\left.\left[\mathrm{CaCl}_{2}\right]=0.5 \mathrm{wt} \%\right)$ and (b) an example of a force curve grid on a Ca-alginate microparticle, acquired during the experiment using an inverted optical microscope coupled with AFM.

An example of a force curve is shown in Figure 15. The vertical deflection of the cantilever, proportional to the force, depends on the distance between AFM probe and microparticle surface. During measurement, the AFM probe indents about $320 \mathrm{~nm}$ on the surface (Fig.15), less than $1 \%$ of the diameter of Ca-alginate microparticles $(35 \mu \mathrm{m})$. Thus, the Young's modulus is measured at the microparticle surface.

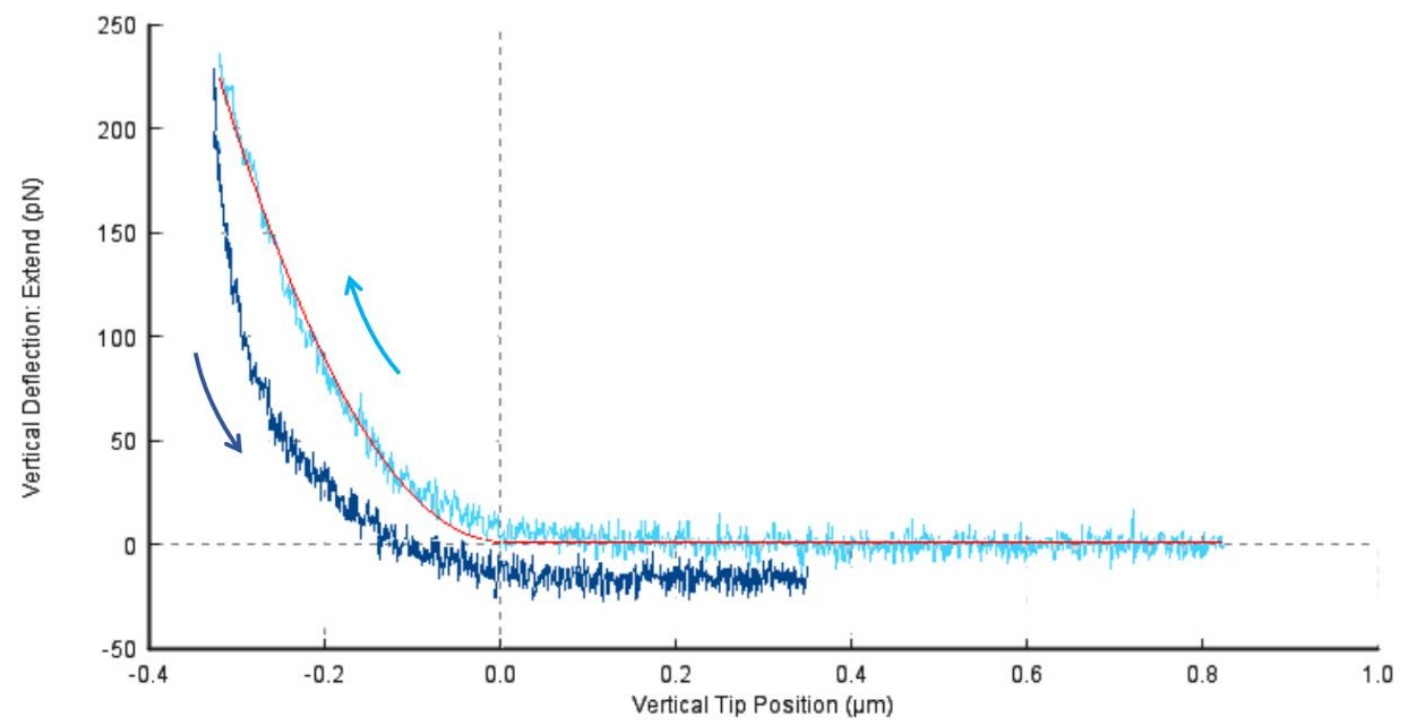

Figure 15: Example of a force curve on a Ca-alginate microparticle: curves relative to cantilever approach and retraction, indicated by arrows, are respectively in light and dark blue; the Hertz Model fit is in red. Zero vertical position shows the point of contact between cantilever and microparticle where no force is applied and the distance between cantilever and sample surface is zero. The negative values of the abscissa, in absolute value, are the indentation, which is the bead surface deformation.

Furthermore, we find that the Young's modulus of Na-alginate microparticles is of the order of $\mathrm{MPa}$, whereas the Young's modulus of Ca-alginate microparticles is $47 \pm 43 \mathrm{kPa}$. Obviously, 
there is a significant decrease in Young's modulus from Na-alginate microparticles to $\mathrm{Ca}$ alginate microparticles. This is due to the swelling observed during the gelation process when $\mathrm{Na}$-alginate microparticles are immersed in $\mathrm{CaCl}_{2}$ solution. Consequently, Ca-alginate microparticles contain more water than $\mathrm{Na}$-alginate microparticles, reducing the Young's modulus.

Moreover, the Young's modulus of Ca-alginate microparticles $(47 \pm 43 \mathrm{kPa})$ is of the same order as that of RBCs $(26 \pm 7 \mathrm{kPa})$, where a similar indentation of $200 \mathrm{~nm}$ was reported using a similar AFM probe. (Dulińska et al., 2006) It should be noted that larger Young's modulus values have been found in pathological RBCs (e.g. $90 \pm 20 \mathrm{kPa}$ for erythrocytes with G6PD deficiency) (Dulińska et al., 2006) and in RBCs that have undergone specific treatments (e.g. 191 $\pm 28 \mathrm{kPa}$ for formalin-treated cells) (Girasole et al., 2012). Nevertheless, the Young's modulus of Naalginate microparticles ( $\mathrm{MPa}$ ) remains beyond the latter range. Gelation can therefore be considered a key step in producing microparticles with mechanical properties close to those of RBCs.

On the other hand, we also find that the Young's modulus varies substantially depending on the measuring point on the microparticle surface (Fig.S9 in the supplementary material). Moreover, this variation also depends on the individual microparticle, even though all are prepared in the same way and come from the same experimental batch. This is actually reflected by the relatively high standard deviation in results $(E=47 \pm 43 \mathrm{kPa}$ ). Surface irregularities can lead to Young's modulus variations; however here, the surface of both Naalginate and Ca-alginate microparticles is smooth according to SEM photographs (Fig.11). Thus, it may be reasonable to attribute the variation to the microparticles' porous inner structure (Fig. 12 and 16). As shown in Figure 16, the thickness of the shell, defined as the space between the surface and the closest inner pore of the microparticle, varies greatly. Because of the heterogeneity of the porous inner structure, this thickness can be of the same order $(500 \mathrm{~nm})$ as the indentation of the cantilever probe $(320 \mathrm{~nm})$, or larger (in $\mu \mathrm{m}$ range). Consequently, the varying Young's moduli measured may be the result of varying shell thickness. However, further investigations would be required to validate this explanation.

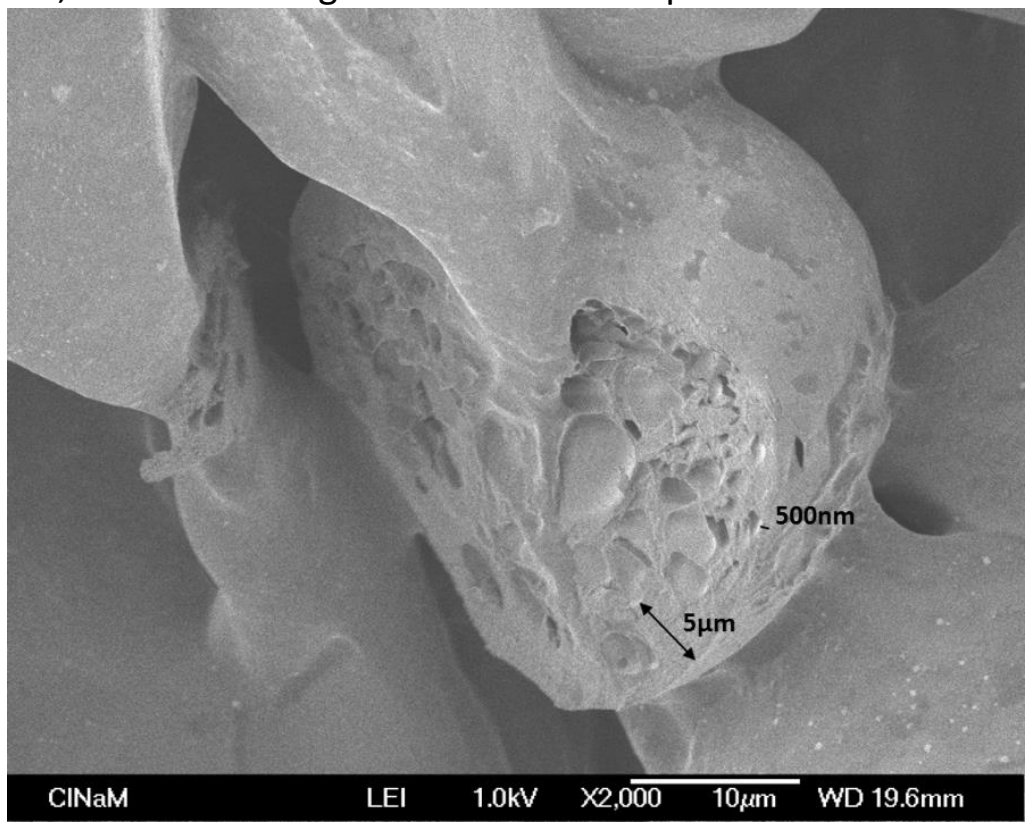

Figure 16: SEM photograph of the inner structure of a Ca-alginate microparticle.

\section{Conclusions and perspectives}


In this article, we present a microfluidic method of producing monodispersed hydrogel microparticles of $\mathrm{Na}-/ \mathrm{Ca}$-alginate with controllable sizes (micrometer range) and mechanical properties without using surfactant. Here, our ultimate aim was to produce microparticles that mimic red blood cells (RBCs). Ex situ gelation, used for the transformation from Naalginate to Ca-alginate microparticles, proves key to obtaining the desired microparticle properties, such as insolubility in water and RBC-like mechanical properties. For both Naalginate and $\mathrm{Ca}$-alginate microparticles, a smooth surface and a porous inner structure are observed under a scanning electron microscope. A platform of microgrippers was successfully developed to manipulate the microparticles. The Young's modulus, measured using an atomic force microscope on the surface of the Ca-alginate microparticles generated, is of the same order as that of RBCs. Combined with size control to micrometer range, this confirms the feasibility of using Ca-alginate microparticles to mimic RBCs and subsequently study the aggregation of RBCs under in vivo and in situ flow conditions with ultrasonic imaging. Moreover, we describe a simple method of separating $\mathrm{Na}$-alginate and $\mathrm{Ca}$-alginate microparticles from solution by gentle drying at room temperature.

Interesting future perspectives include studying parameters such as the concentration of $\mathrm{CaCl}_{2}$ and $\mathrm{pH}$, to determine whether they have an impact on the mechanical properties of Caalginate microparticles. This would lead to better understanding and control of microparticle mechanical properties.

\section{Conflicts of interest}

There are no conflicts of interest to declare.

\section{Acknowledgements}

First, we are grateful to ANR CUMBA (ANR-15-CE19-0017-03) for its financial support of this work. Second, we would like to thank Michel Maton (Alliance Gums and Industries) for his kind provision of sodium alginate. Third, we are also grateful to Mehdi Lagaize for providing technical support for these experiments and Cecilia Colomes for experimental assistance during her graduate training period. Last but not least, we thank Marjorie Sweetko for English revision.

\section{References}

Dulińska, I., Targosz, M., Strojny, W., Lekka, M., Czuba, P., Balwierz, W., Szymoński, M., 2006. Stiffness of normal and pathological erythrocytes studied by means of atomic force microscopy. Journal of Biochemical and Biophysical Methods 66, 1-11.

Freitas, S., Merkle, H.P., Gander, B., 2005. Microencapsulation by solvent extraction/evaporation: reviewing the state of the art of microsphere preparation process technology. Journal of Controlled Release 102, 313-332.

Girasole, M., Dinarelli, S., Boumis, G., 2012. Structure and function in native and pathological erythrocytes: A quantitative view from the nanoscale. Micron 43, 1273-1286.

Håti, A.G., Bassett, D.C., Ribe, J.M., Sikorski, P., Weitz, D.A., Stokke, B.T., 2016. Versatile, cell and chip friendly method to gel alginate in microfluidic devices. Lab on a Chip 16, 3718-3727. 
Ildefonso, M., Candoni, N., Veesler, S., 2012. A Cheap, Easy Microfluidic Crystallization Device Ensuring Universal Solvent Compatibility. Organic Process Research and Development 16, 556-560.

Lee, K.Y., Mooney, D.J., 2012. Alginate: Properties and biomedical applications. Progress in Polymer Science 37, 106-126.

Lee, K.Y., Yuk, S.H., 2007. Polymeric protein delivery systems. Progress in Polymer Science 32, 669-697. Monchy, R.d., Rouyer, J., Destrempes, F., Chayer, B., Cloutier, G., Franceschini, E., 2018. Estimation of polydispersity in aggregating red blood cells by quantitative ultrasound backscatter analysis. The Journal of the Acoustical Society of America 143, 2207-2216.

Ouwerx, C., Velings, N., Mestdagh, M.M., Axelos, M.A.V., 1998. Physico-chemical properties and rheology of alginate gel beads formed with various divalent cations. Polymer Gels and Networks 6, 393-408.

Pittermannová, A., Ruberová, Z., Zadražil, A., Bremond, N., Bibette, J., Štěpánek, F., 2016. Microfluidic fabrication of composite hydrogel microparticles in the size range of blood cells. RSC Advances 6 , 103532-103540.

Rondeau, E., Cooper-White, J.J., 2008. Biopolymer Microparticle and Nanoparticle Formation within a Microfluidic Device. Langmuir 24, 6937-6945.

Stephenson, R., Stuart, J., 1986. Mutual binary solubilities: water-alcohols and water-esters. Journal of Chemical and Engineering Data 31, 56-70.

Sugaya, S., Yamada, M., Hori, A., Seki, M., 2013. Microfluidic production of single micrometer-sized hydrogel beads utilizing droplet dissolution in a polar solvent, Biomicrofluidics, p. 54120.

Utech, S., Prodanovic, R., Mao, A.S., Ostafe, R., Mooney, D.J., Weitz, D.A., 2015. Microfluidic Generation of Monodisperse, Structurally Homogeneous Alginate Microgels for Cell Encapsulation and 3D Cell Culture. Advanced Healthcare Materials 4, 1628-1633.

Yamada, M., Sugaya, S., Naganuma, Y., Seki, M., 2012. Microfluidic synthesis of chemically and physically anisotropic hydrogel microfibers for guided cell growth and networking. Soft Matter 8, 31223130.

Yang, J., Katagiri, D., Mao, S., Zeng, H., Nakajima, H., Uchiyama, K., 2015. Generation of controlled monodisperse porous polymer particles by dipped inkjet injection. RSC Advances 5, 7297-7303.

Zhang, H., Tumarkin, E., Sullan, R.M.A., Walker, G.C., Kumacheva, E., 2007. Exploring Microfluidic Routes to Microgels of Biological Polymers. Macromolecular Rapid Communications 28, 527-538.

Zhang, S., Guivier-Curien, C., Veesler, S., Candoni, N., 2015. Prediction of sizes and frequencies of nanoliter-sized droplets in cylindrical T-junction microfluidics. Chemical Engineering Science 138, 128139. 


\section{Supplementary Material for: \\ A microfluidic method generating monodispersed microparticles with controllable sizes and mechanical properties}

Cheng Zhang ${ }^{1}$, Romain Grossier ${ }^{1}$, Leda Lacaria ${ }^{2}$, Felix Rico ${ }^{2}$, Nadine Candoni ${ }^{1}$, Stéphane Veesler ${ }^{1}$

${ }^{1}$ CNRS, Aix-Marseille Université, CINaM (Centre Interdisciplinaire de Nanosciences de Marseille), Campus de Luminy, Case 913, F-13288 Marseille Cedex 09, France

${ }^{2}$ Adhesion and Inflammation Lab (LAI)/INSERM U1067 CNRS UMR 7333, 163, avenue de Luminy, Case 937; 13288 Marseille Cedex 09, France

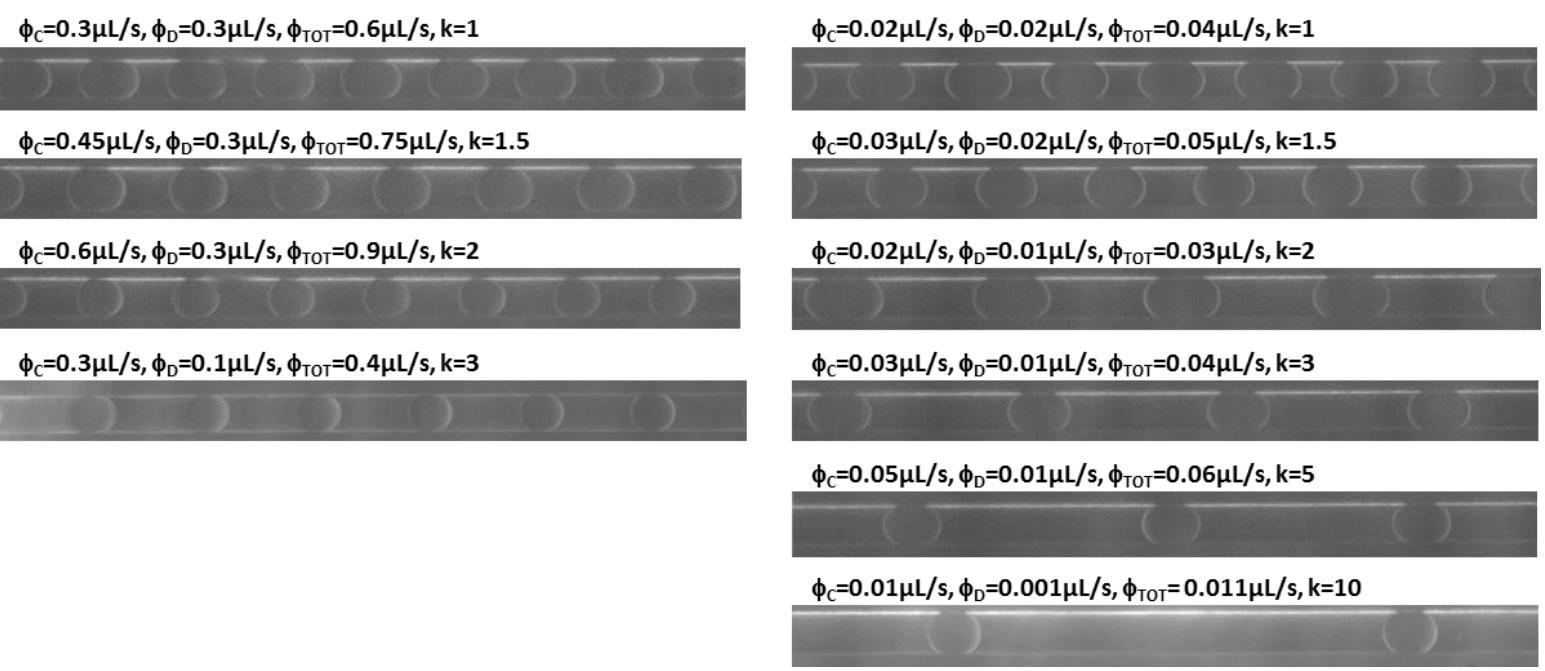

Figure S1: Observation of microdroplets generated in a channel (ID 150 $\mu \mathrm{m}$ ) under different conditions: flow rates, the ratio of flow rates $k$ between continuous phase and dispersed phase, and total flow rate $\phi_{\text {TOT }}$. 


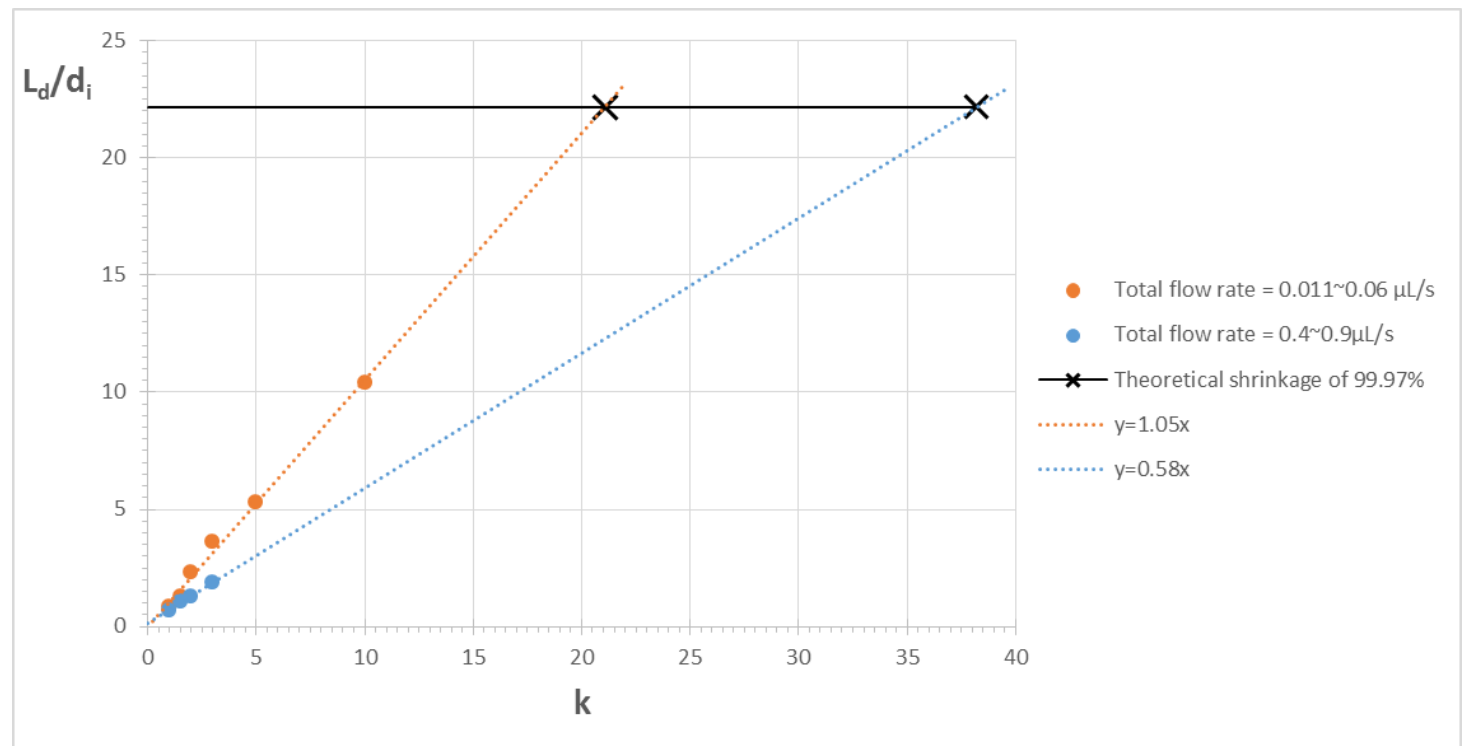

Figure S2: Estimation of $L_{d} / d_{i}$ as a function of $k$ from Figure S1. Crosses show the theoretical $k$ for $L_{d} / d_{i}=22.2$, calculated with eq. (3), to obtain a shrinkage rate of $99.97 \%$ in volume for each total flow rate.

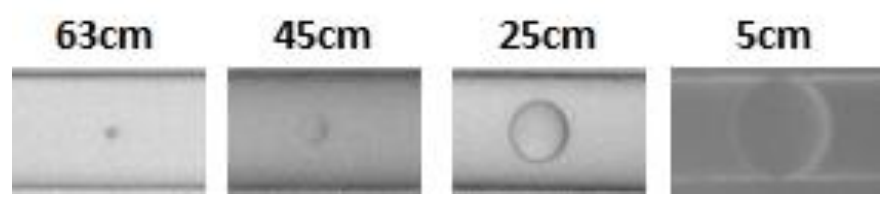

Figure S3: Observation of microdroplet shrinkage at different distances from the T-junction, for the following operational parameters: $k=40, \phi_{C}=0.2 \mu \mathrm{L} / \mathrm{s}, \phi_{D}=0.005 \mu \mathrm{L} / \mathrm{s}$. Channel ID $150 \mu \mathrm{m}$.

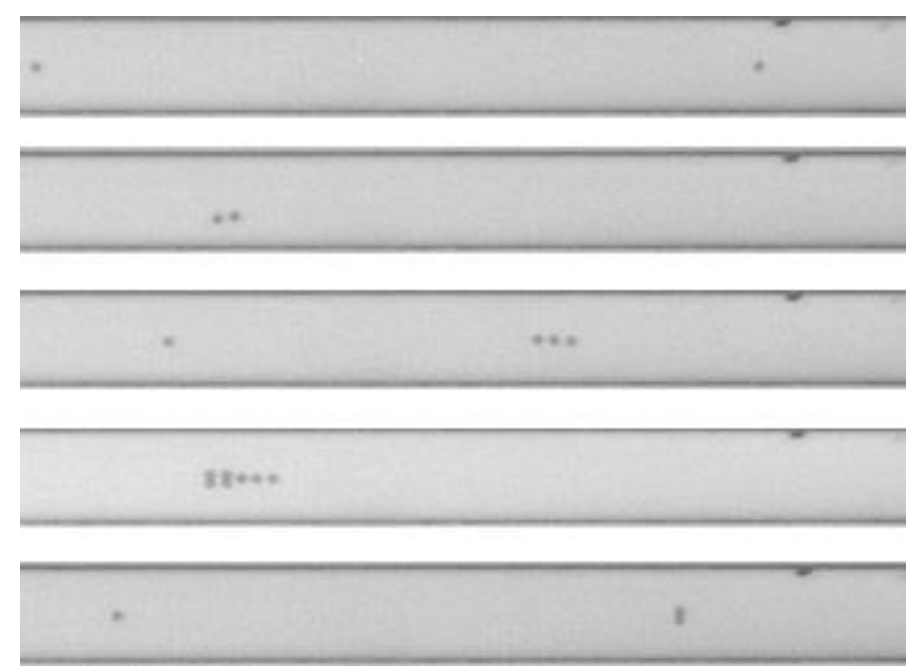

Figure S4: Observation of microdroplets at $63 \mathrm{~cm}$ from the T-junction, for the following operational parameters: $k=40, \phi_{C}=0.2 \mu \mathrm{L} / \mathrm{s}, \phi_{D}=0.005 \mu \mathrm{L} / \mathrm{s}$. Channel ID $150 \mu \mathrm{m}$. 


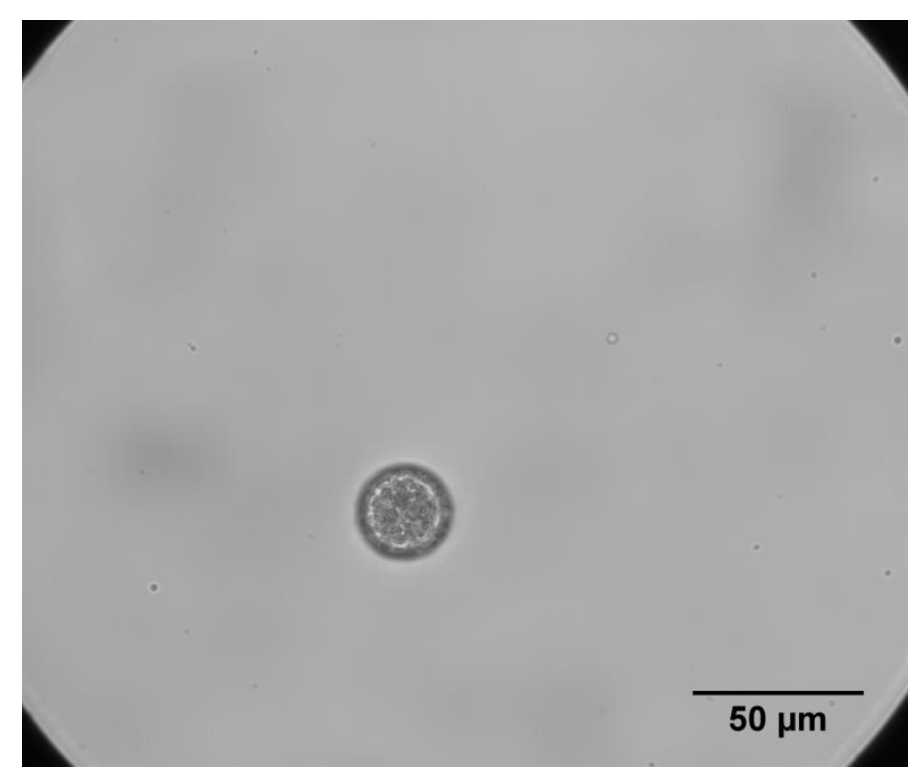

Figure S5: Optical micrograph of Na-alginate microparticle of Fig.9a in suspension in DMC.
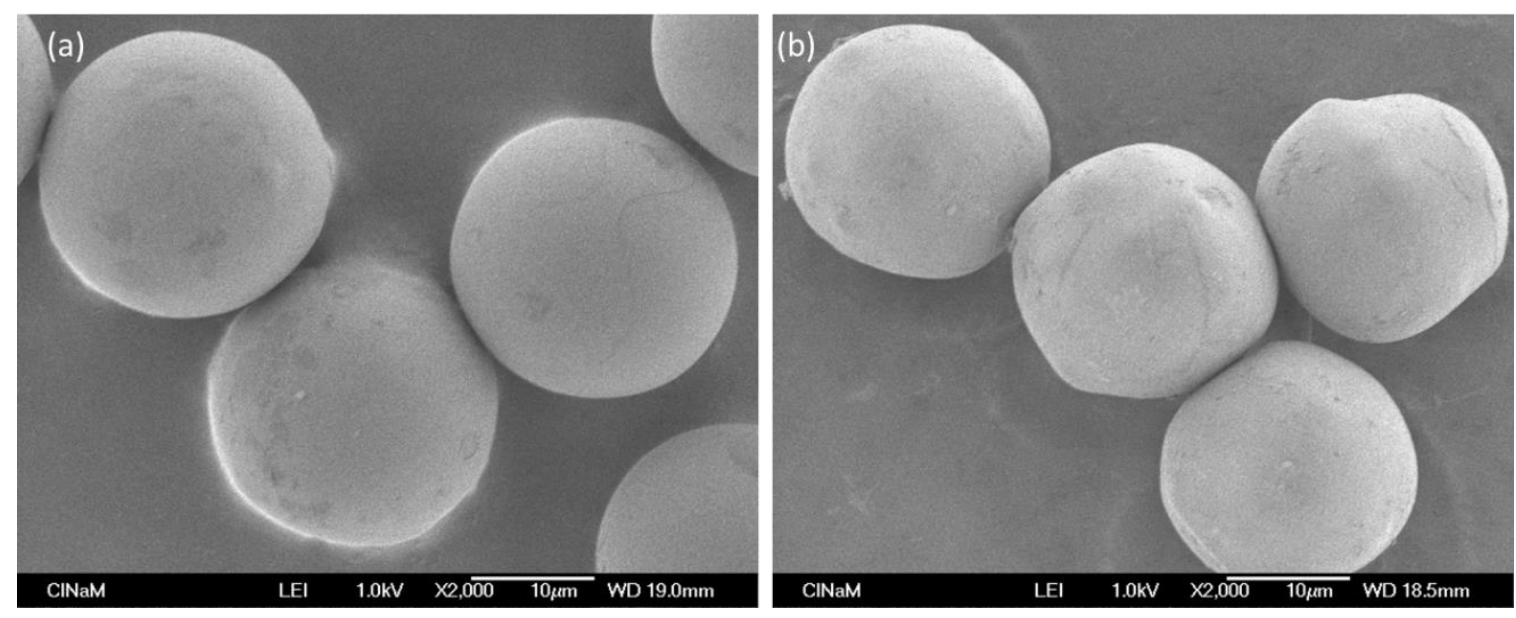

Figure S6: SEM photographs of (a) Na-alginate and (b) Ca-alginate microparticles (formed in a $0.5 \mathrm{wt} \%$ $\mathrm{CaCl}_{2}$ solution). Experimental conditions: $\mathrm{C}_{\mathbf{i}}=0.25 \mathrm{wt} \%, \mathrm{~L}=19 \mathrm{~cm}, \mathrm{DMC}$ flow rate $=0.15 \mu \mathrm{l} / \mathrm{s}$ and $\mathrm{k}=50$.

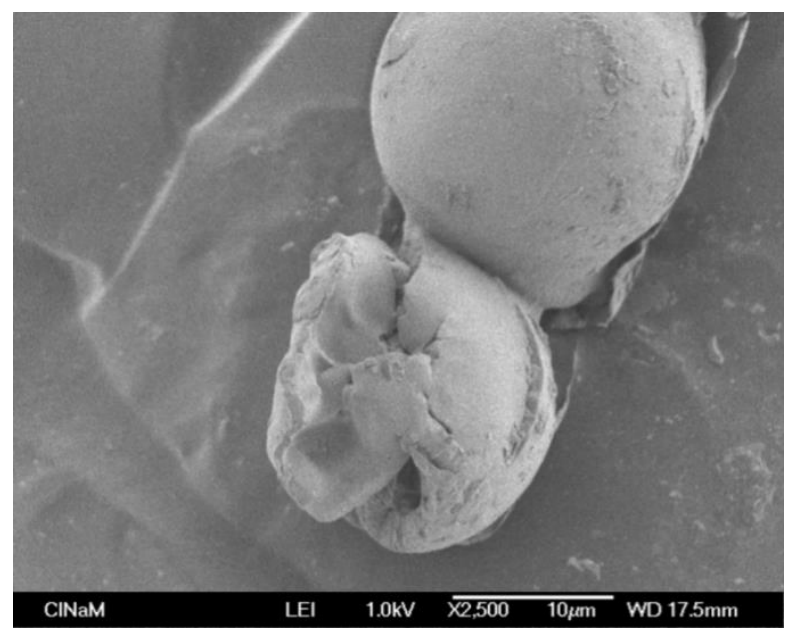

Figure S7: SEM photograph of a squeezed Ca-alginate microparticle (formed in a $0.5 \mathrm{wt} \% \mathrm{CaCl} 2$ solution). (Same experimental conditions as for Figure S6) 


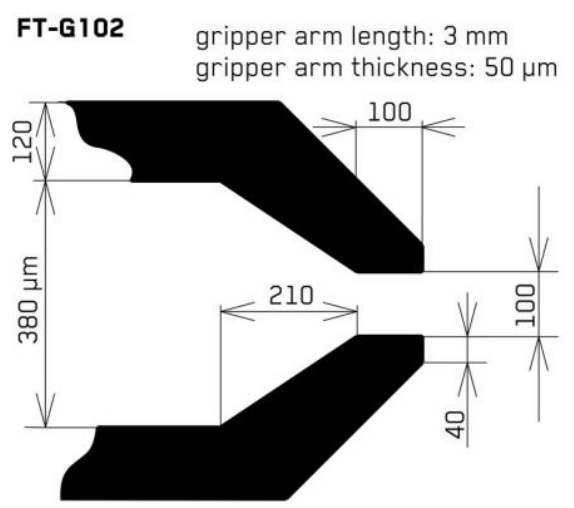

Figure S8: Dimension of the FT-G 102 Force Sensing microgrippers from FemtoTools official site (https://www.femtotools.com/products/ft-mta03/accessories/ft-g-force-sensing-microgripper).
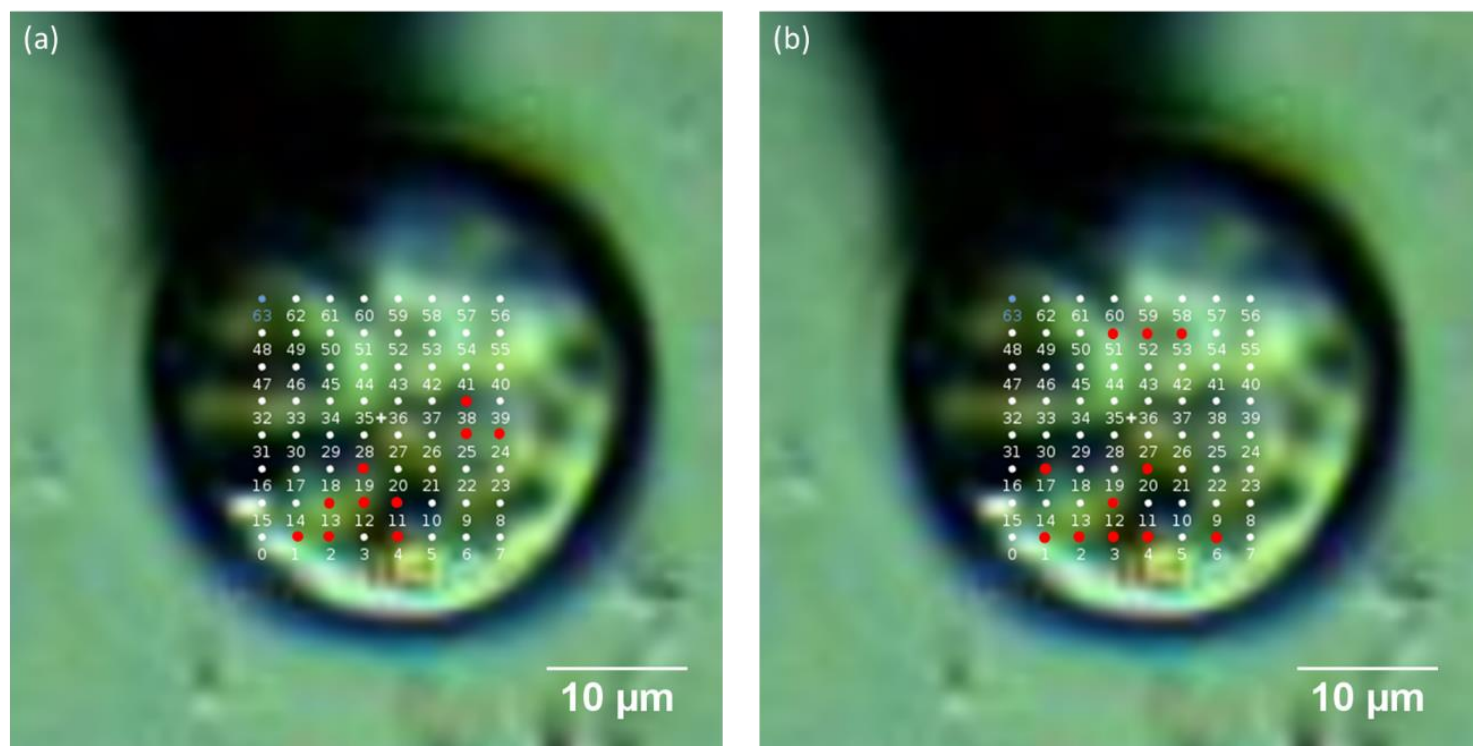

Figure 59: Images of force curve grid on two different Ca-alginate microparticles from the same experimental batch. Red points show the distribution of Young's modulus maxima.

Mathematical derivation of the fitting equation in Figure 7:

From Figure 6a, we have the fitting equation (1) of power law showing $d_{f}$ as a function of $c_{i}$ and $d_{i}$. $d_{f}=A_{C i} \times d_{i}^{\alpha}$

Here, the constant factor $A_{c_{i}}$ varies depending on $C_{i}$. The exponent $\boldsymbol{\alpha}$ is about 0.3-0.4. We apply it to equation (5) in the article.

$C_{f}=C_{i} \times\left(\frac{d_{i}}{d_{f}}\right)^{3}=C_{i} \times\left(\frac{d_{i}}{A_{C i} \times d_{i}^{\alpha}}\right)^{3}=\left(\frac{C_{i}}{A_{C i}^{3}}\right) \times d_{i}^{3-3 \alpha}$

In our experiments, $\left(\frac{C_{i}}{A_{C i}^{3}}\right)$ varies from 0.001 to 0.005 and $(3-3 \alpha)$ varies from 1.8 to 2.1 .

Consequently, equation (2) corresponds well with the fitting equation shown in Figure 7: $C_{f}=0.0025 \times$ $d_{i}^{1.97}$. 